\title{
Unidades geomorfológicas y distribución de facies sedimentarias en la Isla Cayos de Alburquerque, Reserva de Biosfera Seaflower, Caribe colombiano
}

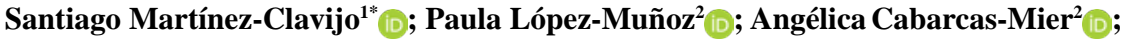 \\ Jose Luis Payares-Varela $^{1}\left(\mathbb{D}\right.$; Julio Gutiérrez ${ }^{2}$; ; Julián Quintero² $^{2}$
}

Forma de citar: Martínez-Clavijo, S.; López-Muñoz, P.; Cabarcas-Mier, A.; Payares-Varela, J.L.; Gutiérrez, J.; Quintero, J. (2021). Unidades geomorfológicas y distribución de facies sedimentarias en la Isla Cayos de Alburquerque, Reserva de Biosfera Seaflower, Caribe colombiano. Boletín de Geología, 43(3), 143-164. https:// doi.org/10.18273/revbol.v43n2-2021007

\begin{abstract}
Resumen
Se caracterizaron las unidades geomorfológicas mediante técnicas de sensoramiento remoto (imágenes satelitales y acústico) y se determinó la distribución de las facies sedimentarias validadas con datos in situ en la Isla Cayos de Alburquerque como una contribución al conocimiento de la Reserva de Biosfera de Seaflower. Esta isla cayos presenta una geomorfología típica de un atolón con Bajos arrecifales, Cuenca lagunar, Terraza lagunar, Terraza prearrecifal, Talud y Arrecife periférico, el cual presenta una extensión aproximada de 6 km que son impactados por el fuerte oleaje originados por los vientos alisios del noreste. Se lograron establecer 10 facies sedimentarias de composición biolitoclástica y bioclástica de formaciones coralinas y del basamento volcánico del atolón, con una distribución heterogénea. Este estudio permite establecer una línea base para el conocimiento de la dinámica del transporte y depósito de los sedimentos en las plataformas arrecifales.
\end{abstract}

Palabras clave: Distribución del sedimento; Geomorfología; Facies sedimentarias; Caribe colombiano; Sensores remotos.

\section{Geomorphological units and distribution of sedimentary facies in the Alburquerque Key Island, Seaflower Biosphere Reserve, Colombian Caribbean}

\begin{abstract}
Geomorphological units were characterized by remote sensing techniques (satellite images and acoustic) and the distribution of sedimentary facies was validated with in situ data in Albuquerque Key Island as a contribution to the knowledge of the Seaflower Biosphere Reserve. The Key Island presents the typical atoll geomorphology with Low reefs, Lagoon basin, Lagoon terrace, Prereef terrace, Slope, and Peripheral reef, which presents an approximate extension of $6 \mathrm{~km}$; these reefs are impacted by the strong waves originated by the northeast trade winds. Ten sedimentary facies of biolithic and bioclastic composition of coral formations and the atoll volcanic base were established, with a heterogeneous distribution. This study provides a baseline for understanding the dynamics of sediment transport and deposition on reef platforms.
\end{abstract}

Keywords: Sediment distribution; Geomorphology; Sedimentary facies; Colombian Caribbean; Remote sensing.

\footnotetext{
${ }^{1}$ Grupo de Investigación en Oceanología, Escuela Naval de Cadetes "Almirante Padilla”, Cartagena, Colombia. $(*)$ santiagobm86@gmail.com; jlpayares@enap.edu.co

${ }^{2}$ Grupo de Investigación Zona Costera, Centro de Investigaciones Oceanográficas e Hidrográficas del Caribe, Cartagena, Colombia. paulaalopezque@gmail.com; angelicacabarcas@gmail.com; jGutierrez@dimar.mil.co; julian.quintero@armada.mil.co
} 


\section{Introducción}

Los atolones y las plataformas arrecifales son áreas compuestas en su mayoría por sedimentos bioclásticos entre arenas y gravas de carbonato poco consolidados (Woodroffe, 2008), provenientes de arrecifes coralinos adyacentes. Estas islas al ser de poco tamaño, tener poca elevación y dependientes de los sedimentos coralinos se vuelven vulnerables al impacto del cambio climático y al aumento del nivel medio del mar (Kench y Brander, 2006; Perry et al., 2011; Li et al., 2020), y son objeto de un creciente interés científico debido a las preocupaciones sobre su estabilidad futura (Woodroffe, 2008; Rankey, 2011; Li et al., 2020). Por tal motivo, las investigaciones, entre otros enfoques, se orientan al análisis de la distribución de los sedimentos.

El análisis de la distribución de los sedimentos ha sido considerablemente usado por los geólogos para clasificar los ambientes sedimentarios y para explicar la dinámica del transporte (Venkatramanan et al., 2011). Según Abdulkarim et al. (2014), la composición de los sedimentos se ve afectada por la acción del oleaje y la marea, las corrientes litorales y la composición mineralógica de la costa, por lo que la distribución en el tamaño de grano del sedimento en una playa arenosa varía en función de las condiciones hidrodinámicas. La distribución de los sedimentos a lo largo de la playa es el resultado complejo de la interacción entre la fuente del sedimento, la energía del oleaje y la pendiente en la que la playa está establecida. La intensidad en la acción del oleaje en la zona litoral redeposita y ordena el tamaño de grano del sedimento; por lo tanto, la composición del sedimento de la playa no solo se ve afectada por la hidrodinámica, sino por la cantidad de materiales clásticos suministrados a la costa. Además, el tamaño de grano y la composición de carbonato de calcio son atributos que permiten la caracterización estructural del terreno de un lugar que condiciona las formas de vida presentes en los distintos ambientes, al tiempo que proporcionan información sobre los cambios del suelo, ya sea por causas naturales o antrópicas (Martínez-Clavijo, 2013). Los parámetros utilizados para describir la distribución de los sedimentos se dividen en cuatro grupos principales: a) el tamaño promedio, b) la desviación estándar de acuerdo con el promedio, c) la asimetría, d) la curtosis, el grado de concentración de los granos de acuerdo con el promedio (Blott y Pye, 2001).

Las investigaciones científicas de arrecifes coralinos en Colombia se han encaminado en desarrollar el análisis descriptivo de la composición y ubicación de sus unidades ecológicas, el grado de exposición al oleaje, el tipo de sustrato, la inclinación batimétrica, el relieve y el tipo de inclinación del sustrato, así como en realizar mapas ecológicos marinos para todas las áreas oceánicas del Caribe colombiano (Díaz et al., 2000), y esquemas espaciales de la zonación ecológica, morfológica y comunidades bentónicas de los arrecifes coralinos de la Reserva de Biosfera Seaflower (RBS) (San Andrés, Providencia y Santa Catalina, Quitasueño, Alburquerque, Courtown o Bolívar, Roncador y Serrana) (Díaz, 2005; Sánchez et al., 2005). Sin embargo, la mayoría de estos estudios han ahondado en metodologías específicas orientados a la inspección visual: buceo, bio-transectos y fotográficas aéreas e in situ. No obstante, estos estudios están desactualizados y requieren de tener una periodicidad de actualización de cada 3 a 5 años (CCO, 2015). Debido a esto, se deben desarrollar nuevas metodologías, que implementen procesos y sistemas de información geográfica para contribuir al mejoramiento en la cantidad, calidad y precisión de los productos de amplio espectro (i.e. sensores remotos), que aporten de esta manera al desarrollo marítimo de la Nación (CCO, 2015).

Es por ello, que las investigaciones con el uso de sensores remotos se han fortalecido en las últimas décadas debido a las rápidas alteraciones asociadas al cambio climático y al crecimiento del estrés antropogénico sobre los ecosistemas marinos (arrecifes de coral, pastos marinos, manglares) (Brown y Collier, 2008; Brown y Blondel, 2009; Ierodiaconou et al., 2011; Calvert et al., 2015). Las técnicas de sensoramiento por ejemplo imágenes satelitales, radiometría in situ y acústicas, son reconocidas como las técnicas remotas más eficientes, no invasivas y no destructivas, para mapear y monitorear los fondos oceánicos a gran escala (Anderson et al., 2008; Contreras-Silva et al., 2012). Estas permiten la obtención de imágenes tridimensionales con alta resolución de la superficie del fondo oceánico (López-Orrego et al., 2011). Así como, de determinar las características del fondo marino (Freitas et al., 2005; Medialdea et al., 2008; Ostrovsky y Tęgowski, 2010) y tipos de sedimentos que presentan (Restrepo et al., 2007; Paschke, 2010; Carreño et al., 2011), lo que facilita una visión completa del ambiente pelágico y bentónico marino. De forma que esta información resulta esencial para el manejo efectivo del medioambiente marino, ayudando a los científicos a predecir con precisión el impacto en los hábitats significativos para la conservación de alto valor económico (Kenny et al., 2003). 
La Isla Cayos de Alburquerque (ICAlb) hace parte del departamento Archipiélago de San Andrés, Providencia y Santa Catalina, declarado como Reserva de Biosfera Seaflower (RBS) desde el año 2000 por la Organización de las Naciones Unidas para la Educación, la Ciencia y la Cultura (UNESCO); en el año 2005 contaba con un área aproximada de $180.000 \mathrm{~km}^{2}$, de los cuales menos del 1\% eran áreas emergidas y una porción de 65.018 $\mathrm{km}^{2}$ como Área Marina Protegida (AMP) (AbrilHoward et al., 2012); hoy en día, la RBS cuenta con

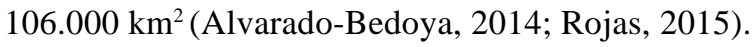

Teniendo en cuenta que la RBS se ha convertido en uno de los iconos más representativos de la protección marina en Colombia, ya que alberga la tercera barrera coralina, más grande del mundo, se muestra como una importante estrategia de conservación in situ y es un escenario de desarrollo sostenible donde se preservan los servicios ecosistémicos, así como el patrimonio natural y cultural (CORALINA, 2004; SantosMartínez et al., 2009), la Comisión Colombiana del Océano (CCO) junto con otras instituciones crearon un programa de investigación científica marina en esta área, dando paso a una serie de expediciones que constituyen un esfuerzo articulado por múltiples entidades del orden nacional en pro de la generación de conocimiento y desarrollo tecnológico. Sin embargo, una de las principales limitantes para aumentar el conocimiento en la RBS, es la falta de información disponible (primaria o secundaria). El único estudio que ha profundizado en recopilar información de diferentes metodologías es el de Díaz et al. (2000), el cual desarrolló un plan sistemático de investigación acorde con las necesidades de información para adelantar planes y estrategias de manejo del ecosistema, dentro de los lineamientos del Programa Nacional de las Ciencias y Tecnologías del Mar. Este documento ha sido de vital importancia para identificar y describir las unidades geomorfológicas y ecológicas, presentes en el área de la RBS, que hoy en día se conocen.

Este trabajo se deriva de la VII Expedición Científica Seaflower 2018, cuyo principal objetivo es caracterizar las unidades geomorfológicas a partir de técnicas de sensoramiento remoto y determinar la distribución de los sedimentos de la ICAlb como aporte al conocimiento y actualización de la geomorfología de la RBS.

\section{Localización geográfica y datos climáticos}

La ICAlb se encuentra a $37 \mathrm{~km}$ al sur de la isla de San Andrés y $190 \mathrm{~km}$ al este de la costa nicaragüense; sus coordenadas son $12^{\circ} 10^{\prime}$ norte y $81^{\circ} 51^{\prime}$ oeste (Figura 1 ). Tiene una forma casi circular, aproximadamente $5,5 \mathrm{~km}$ E-O y 4,5 km N-S. Dos islas pequeñas, North Cay y South Cay, se elevan hasta $2 \mathrm{~m}$ por encima del nivel del mar medio detrás del arrecife de barrera hacia el mar y están separadas entre sí por un canal poco profundo de 250 m (Díaz et al., 1996).

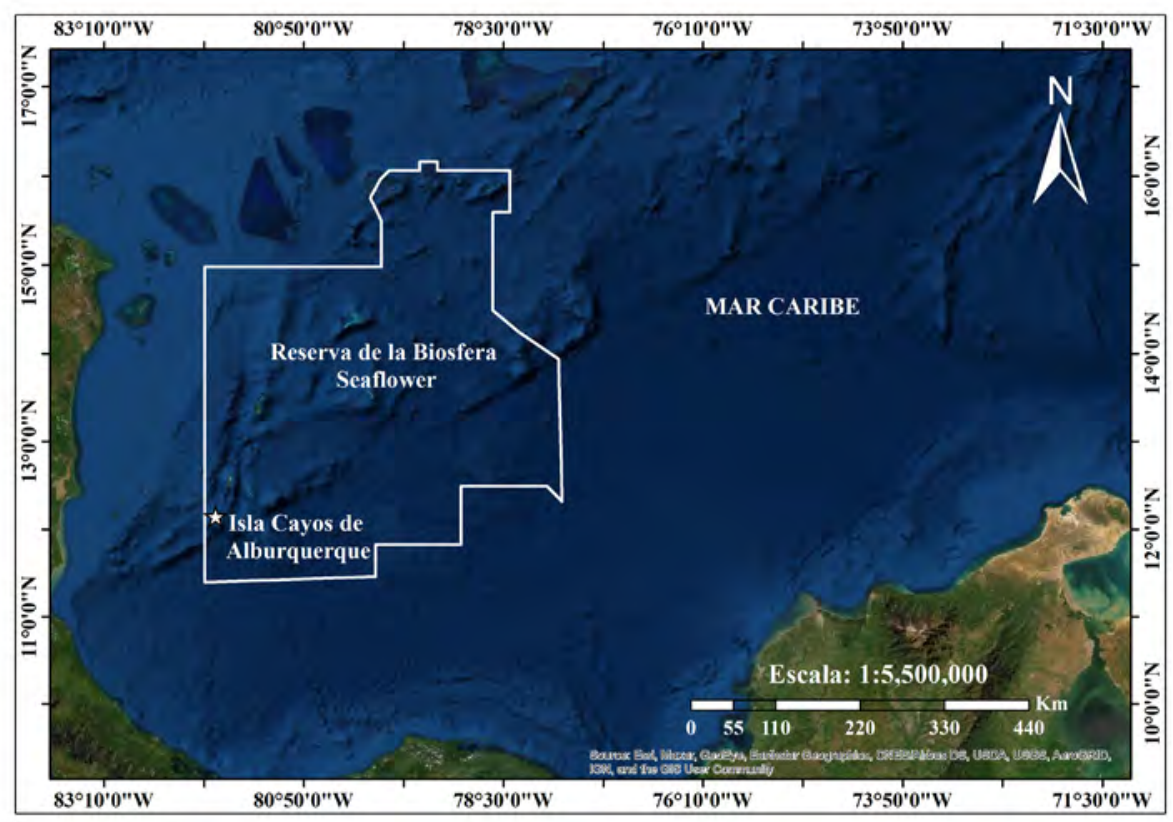

Figura 1. Delimitación de la Reserva de Biosfera Seaflower (RBS) y ubicación geográfica de la Isla Cayos de Alburquerque (en forma de estrella); imagen obtenida con el software ArcMap. 
La temperatura media anual del aire es de $27,4^{\circ} \mathrm{C}$, con un rango de $1^{\circ} \mathrm{C}$ en valores mensuales. La precipitación anual medida en San Andrés es de aproximadamente $1900 \mathrm{~mm}$, de los cuales más del $80 \%$ se encuentra entre junio y noviembre. Los vientos son intercambios del ENE, con una intensidad media anual de $6,1 \mathrm{~m} / \mathrm{s}$ y variaciones mensuales promedio entre $4,5 \mathrm{~m} / \mathrm{s}$ (mayo, septiembre y octubre) y $6,6 \mathrm{~m} / \mathrm{s}$ (diciembre-enero, julio). Las tormentas esporádicas ocurren principalmente en la segunda mitad del año, y los vientos del oeste o del noroeste alcanzan velocidades de más de $20 \mathrm{~m} / \mathrm{s}$ (Díaz et al., 1996). La temperatura promedio de la superficie del mar es de $27,5^{\circ} \mathrm{C}$, con valores mensuales medios que oscilan entre $26,8^{\circ} \mathrm{C}$ entre febrero y marzo (época seca) y $30,2^{\circ} \mathrm{C}$ entre septiembre y octubre (época lluviosa). La salinidad superficial fluctúa entre 34,00 y 36,30 ppm (González, 1987). Las mareas en los atolones son mixtas con un fuerte componente diurno donde se registran intervalos de actividad entre 0,3 y 0,6 m desde San Andrés (Geister, 1975).

\section{Marco geológico}

El Caribe Colombiano es una zona tectónicamente activa, cuya evolución está relacionada con la interacción de las placas norteamericana, suramericana, Cocos, Caribe y el bloque Panamá-Chocó. El contexto geológico regional de la RBS está vinculado directamente con la evolución tectónica de la placa Caribe. A continuación, se exponen de manera sucinta dos modelos teóricos que explican el origen y evolución de esta corteza oceánica, cuyas diferencias radican en su sitio de formación. La primera teoría está basada en el modelo alóctono, el cual propone que esta placa se originó durante el Mesozoico en un punto caliente de la placa Farallón, ubicada en el océano Pacifico, que se desplazó en dirección este-noreste hasta su posición actual (Ross y Scotese, 1988; Pindell y Barret, 1991; Mann, 1999; Pindell et al., 2005; Pindell y Kennan, 2009; Boschman et al., 2014). La segunda teoría sugiere un modelo autóctono, que relaciona su origen con la apertura del Océano Atlántico en el oeste durante el Mesozoico, muy cerca a su posición actual. Esta modelo sugiere, además, que paralelamente a esta apertura se fue formando un plateu oceánico a partir de una pluma del manto, con un movimiento con respecto a Sudamérica en dirección este, el cual se mantiene hasta la actualidad (Ball et al., 1969; Aubouin et al., 1982a, 1982b; Sykes et al., 1982; Donnelly, 1989; Klitgord y Schouten, 1986; Frisch et al., 1992; Meschede y Frisch, 1998; James, 2006; Rao, 2008).
La RBS está ubicada geográficamente en el Alto de Nicaragua al noroeste de la cuenca Colombia, con una disposición NNE-SSW. Las islas y atolones de la RBS tienen una larga historia geológica que inicia con un vulcanismo de flujos de lava y depósitos piroclásticos y epiclásticos en el Cenozoico temprano, seguido por una subsidencia de estos y depositación de calizas arrecifales de aguas poco profundas (Garzón-Ferreira y Díaz, 2003; Milliman, 1969 en Díaz, 2005; Geister y Díaz, 2007; Carvajal, 2009; Gamboa et al., 2012; Afanador-Franco et al., 2013; Idárraga-García y León, 2019; Idárraga-García et al., 2021). La ICAlb corresponde a un atolón compuesto por dos cayos (North Cay y South Cay) que emergieron sobre el nivel del mar, los cuales presentan tendencias lineales al este y sur, como consecuencia del control tectónico del sistema de fallas Alburqueque-Providencia y el sistema de fallas de Hess; hacia el costado noreste se presentan dos crestas rectilíneas que se extienden unos kilómetros hacia el norte hasta unirse para formar la isla de San Andrés (Geister, 1992; Díaz et al., 1996; Geister y Díaz, 2002; CCO, 2015; Idárraga-García et al., 2021).

\section{Metodología}

\section{Caracterización unidades geomorfológicas}

La caracterización de las unidades geomorfológicas se realizó a partir de técnicas acústicas y ópticas. Las técnicas acústicas a partir de datos batimétricos se usaron para conocer las profundidades de las unidades geomorfológicas. Este levantamiento se realizó a bordo de una lancha utilizando la ecosonda Monohaz ODOM HYDROTRAC II, con un transductor de $200 \mathrm{kHz}$ y con una resolución de $50 \mathrm{~m}$, conectado a un sistema de posicionamiento R7 TRIMBLE y un perfilador de velocidad de sonido AML MINOS X. El levantamiento se llevó a cabo entre el 2 y el 16 de octubre del 2018, en la Expedición Científica Seaflower 2018. Se realizaron desplazamientos paralelos equiespaciados a $200 \mathrm{~m}$ de distancia de cada recorrido. La información acústica se generó con sistemas de coordenadas UTM (Universal Transverse Mercator) y un datum WGS84. Se obtuvo un archivo XYZ; posterior a esto, se convirtieron a coordenadas geográficas, con un total de 4406 pulsos acústicos de la profundidad del fondo de la ICAlb (Figura 2). 


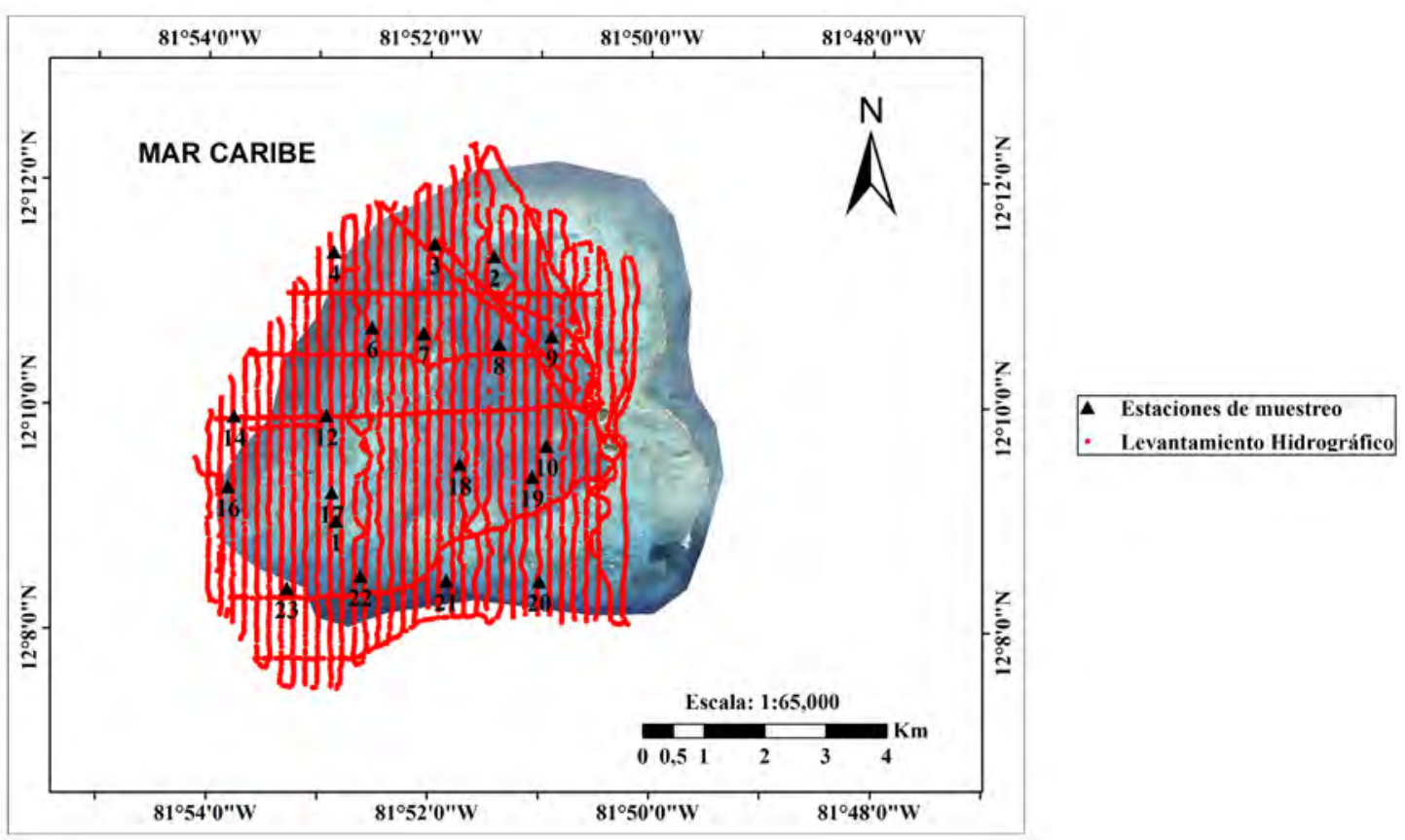

Figura 2. Levantamiento acústico (líneas de color rojo) y ubicación de las estaciones de muestreo sobre la ICAlb. Imagen satelital de la Isla Cayos Alburquerque, RBS (tomado de IGAC, 2016-2017).

Se elaboraron mapas del levantamiento batimétrico en 3D y cartografías temáticas de las unidades geomorfológicas y facies sedimentarias con el software ArcGIS 10.5, utilizando el método de interpolación del vecino más cercano, el cual es uno de los algoritmos más utilizados para hallar el subconjunto de muestras de entrada más cercano a un punto de consulta y aplicar ponderaciones sobre estas basándose en áreas proporcionales para interpolar un valor (Sibson, 1981).

La caracterización geomorfológica se realizó de acuerdo con los cuatro criterios de Geister y Díaz (2007): tipo de sedimento predominante, afectación por la ubicación de las islas en la plataforma del arrecife, la forma del cayo y cobertura vegetal y/o arrecifal. Además, se tuvo en cuenta un quinto criterio no contemplado dentro de la metodología de Geister y Díaz (2007); el comportamiento y evolución del arrecife, ya que los cambios climáticos a escala global inducen nuevas amenazas, incluso para sistemas de arrecifes prístinos que no se encuentren directamente bajo su influencia.

Para la generación de la cartografía temática se utilizaron imágenes Worldview-2 de $2,5 \mathrm{~m}$ de resolución espacial utilizando el modelo de Deep of Penetration (DOP) (Codazzi, 2015) y la segmentación de imagen de Markov (Pantoja-Benavides et al., 2010), generando un Modelo Digital Batimétrico (MDB). Con el fin de interpretar adecuadamente esta información, se realizó un montaje de las imágenes de estudio sobre el MDB, aplicando un grado de transparencia mínimo para diferenciar los relieves y contrastes, que correlaciona con la homogeneidad de los elementos de cada categoría.

Para ejecutar este modelo, se realizó una determinación de la zonación coralina a partir de las bandas espectrales utilizadas, que corresponden a las bandas B1, B2, B3 y B4. La B1 $(0,43-0,52 \mu \mathrm{m})$ refleja las coloraciones azules y violeta, útil para estudios costeros, batimétricos y de aerosol, así mismo refleja todas las tonalidades de color azul, que alcanzan profundidades entre 20 a 30 $\mathrm{m}$ y que definen zonas costeras, arrecifes submarinos y vegetación acuática sumergida; la B2 (0,52-0,60 $\mu \mathrm{m})$ refleja colores verdes que significan naturaleza: plantas, árboles y bosques; la B3 $(0,63-0,69 \mu \mathrm{m})$ refleja los colores rojos y describe los suelos tropicales, entorno construido, tipos de suelo y características geológicas; por último la B4 $(0,76-0,90 \mu \mathrm{m})$ equivale al infrarrojo cercano, describe floraciones de algas, pastos marinos y arrecifes submarinos (Gutiérrez del Olmo et al., 2013). Esto se realizó con el fin de identificar y ubicar la geomorfología presente en la ICAlb.

Posteriormente, se midieron y corrigieron los niveles de reflectancia emitidos por la capa superficial de la columna de agua, afectados por el efecto albedo. Las 
medidas de reflectancia utilizadas se derivaron de la respuesta espectral de un blanco de referencia sumergido a profundidades controladas de manera experimental, con la finalidad de caracterizar el comportamiento de la reflectancia espectral para cada zona DOP en función del ancho de banda del sensor utilizado y del coeficiente de atenuación (IGAC, 2007). Por último, se realizó una interpolación de las zonas DOP obtenidas por la zonación coralina por las bandas espectrales, teniendo en cuenta el coeficiente de atenuación y la calibración de los valores de profundidad estimados a partir de las imágenes satelitales para cada zona.

\section{Distribución del sedimento y facies sedimentarias}

Para la toma de las muestras sedimentológicas se establecieron 24 estaciones, de las cuales solo se obtuvieron 19 estaciones (Figura 2), las restantes se encontraban encima de un parche coralino. En cada estación se tomaron muestras de sedimento superficial del fondo marino con una de draga AMS tipo Van Veen de 6" x 6", operada desde una lancha; estas fueron empacadas en bolsas ziploc y rotuladas con el número de estación y su ubicación geográfica en grados decimales (Tabla 1).

Tabla 1. Número de estación y ubicación geográfica en grados decimales.

\begin{tabular}{cccccc}
\hline No. Estación & Longitud $\left({ }^{\circ}\right)$ & Latitud $\left({ }^{\circ}\right)$ & No. Estación & Longitud $\left({ }^{\circ}\right)$ & Latitud $\left({ }^{\circ}\right)$ \\
\hline $\mathbf{1}$ & $-81,88058$ & 12,14939 & $\mathbf{1 4}$ & $-81,89599$ & 12,16486 \\
$\mathbf{2}$ & $-81,85696$ & 12,18882 & $\mathbf{1 6}$ & $-81,89691$ & 12,15442 \\
$\mathbf{3}$ & $-81,86596$ & 12,19058 & $\mathbf{1 7}$ & $-81,88121$ & 12,1536 \\
$\mathbf{4}$ & $-81,88113$ & 12,18937 & $\mathbf{1 8}$ & $-81,86198$ & 12,15791 \\
$\mathbf{6}$ & $-81,87532$ & 12,17814 & $\mathbf{1 9}$ & $-81,85104$ & 12,15612 \\
$\mathbf{7}$ & $-81,86755$ & 12,17735 & $\mathbf{2 0}$ & $-81,84988$ & 12,1406 \\
$\mathbf{8}$ & $-81,85616$ & 12,17576 & $\mathbf{2 1}$ & $-81,86388$ & 12,14063 \\
$\mathbf{9}$ & $-81,84821$ & 12,17697 & $\mathbf{2 2}$ & $-81,87682$ & 12,14121 \\
$\mathbf{1 0}$ & $-81,8489$ & 12,16076 & $\mathbf{2 3}$ & $-81,88792$ & 12,13937 \\
$\mathbf{1 2}$ & $-81,88212$ & 12,16502 & & & \\
\hline
\end{tabular}

Análisis granulométrico: del sedimento extraído de cada muestra se pesaron 200 g en una balanza analítica digital OHAUS C-T-200 (Figura 3B y 3C), se colocaron en crisoles (Figura 3A) y después se secaron en un horno Symphony a $70^{\circ} \mathrm{C}$ por $48 \mathrm{~h}$ (Figura 3D). Al término del tiempo de secado, se pesaron $100 \mathrm{~g}$ de cada muestra seca (Figura 3B y 3C); posteriormente a esto, se incorporó cada muestra, durante 10 minutos, dentro de una máquina de tamizaje automática Tyler RX29, la cual presenta 13 compartimientos (Figura 3E), cuyos diámetros de malla están determinados con base en la clasificación del tamaño de grano de Wentworth (1922, citado y modificado por Boggs (2009)), y que se encuentran en una columna de forma ascendente, donde se diferencian las partículas de grano de mayor a menor tamaño de un sedimento no consolidado (Boggs, 2009). Esta clasificación se da en guijarro $(4,75 \mathrm{~mm})$, gránulo (3,35 $\mathrm{mm}$ y $2,00 \mathrm{~mm})$, arena muy gruesa $(1,18 \mathrm{~mm})$, arena gruesa $(600 \mu \mathrm{m}$ y $500 \mu \mathrm{m})$, arena media $(425 \mu \mathrm{m}$, $300 \mu \mathrm{m}$ y $250 \mu \mathrm{m})$, arena fina $(150 \mu \mathrm{m}$ y $125 \mu \mathrm{m})$, arena muy fina $(106 \mu \mathrm{m})$ y lodo $(63 \mu \mathrm{m})$ (Tabla 2$)$. Pasado el tiempo del tamizaje, se pesa la muestra de sedimento retenida en cada compartimiento, se registra el valor obtenido en un formato (Figura 3E) y se determina la clasificación textural según el tamaño de grano de Folk (1974) (Tabla 3).

Los índices granulométricos se obtuvieron a través del programa GRADISTAT (Figura 3G) (Blott y Pye, 2001). El programa calcula los parámetros estadísticos de la muestra utilizando el Método de Momento en el lenguaje de programación Microsoft Visual Basic: media, moda $(\mathrm{s})$, clasificación (desviación estándar $(\sigma)$ ), asimetría y curtosis. Los parámetros de tamaño de grano se calculan aritmética, geométrica $(\mu \mathrm{m})$ y logarítmicamente (utilizando la escala phi $(\Phi)$ ) (Krumbein y Pettijohn, 1938). La interpolación lineal también se utiliza para calcular los parámetros estadísticos mediante el método gráfico de Folk y Ward (1957) y obtener descripciones físicas tales como la selección, asimetría y angulosidad (Tabla 4). De igual manera, el programa proporciona una descripción física del grupo de texturas al que pertenece la muestra y el nombre del sedimento según Folk (1954). Además, presenta una tabla que muestra el porcentaje de granos que caen en cada fracción de tamaño (Blott y Pye, 2001). En términos de resultados gráficos, el programa proporciona gráficos de la distribución del tamaño de grano, la distribución acumulativa de los 
datos en unidades métricas y phi, e incluye el diagrama triangular para la clasificación textural según el tamaño de grano definido por Folk (1974). Para conocer espacialmente cómo se agruparon las estaciones con respecto al tamaño del grano, se realizó un análisis de clúster basado en una matriz de similitud a un porcentaje de intervalo de confianza del $90 \%$.

Calcimetría: esta técnica consiste en determinar la cantidad de carbonato de calcio $\left(\mathrm{CaCO}_{3}\right)$ que contiene una muestra, lo cual permite definir su origen continental o biogénico. El término 'lito' significa que el sedimento proviene de la alteración física y/o química de cualquier roca lejana al sitio de depositación. El término 'bio' sugiere una formación de sedimentos por acumulación de organismos calcáreos; el origen en este caso es autóctono (Tabla 5). El contenido de $\mathrm{CaCO}_{3}$ se definió a partir de $0,25 \mathrm{~g}$ de sedimento normalizado adicionando $4 \mathrm{ml}$ de ácido clorhídrico $(\mathrm{HCl})$ al 10\% y empleando el calcímetro de Bernard (Gutiérrez y Bernuil, 2004).
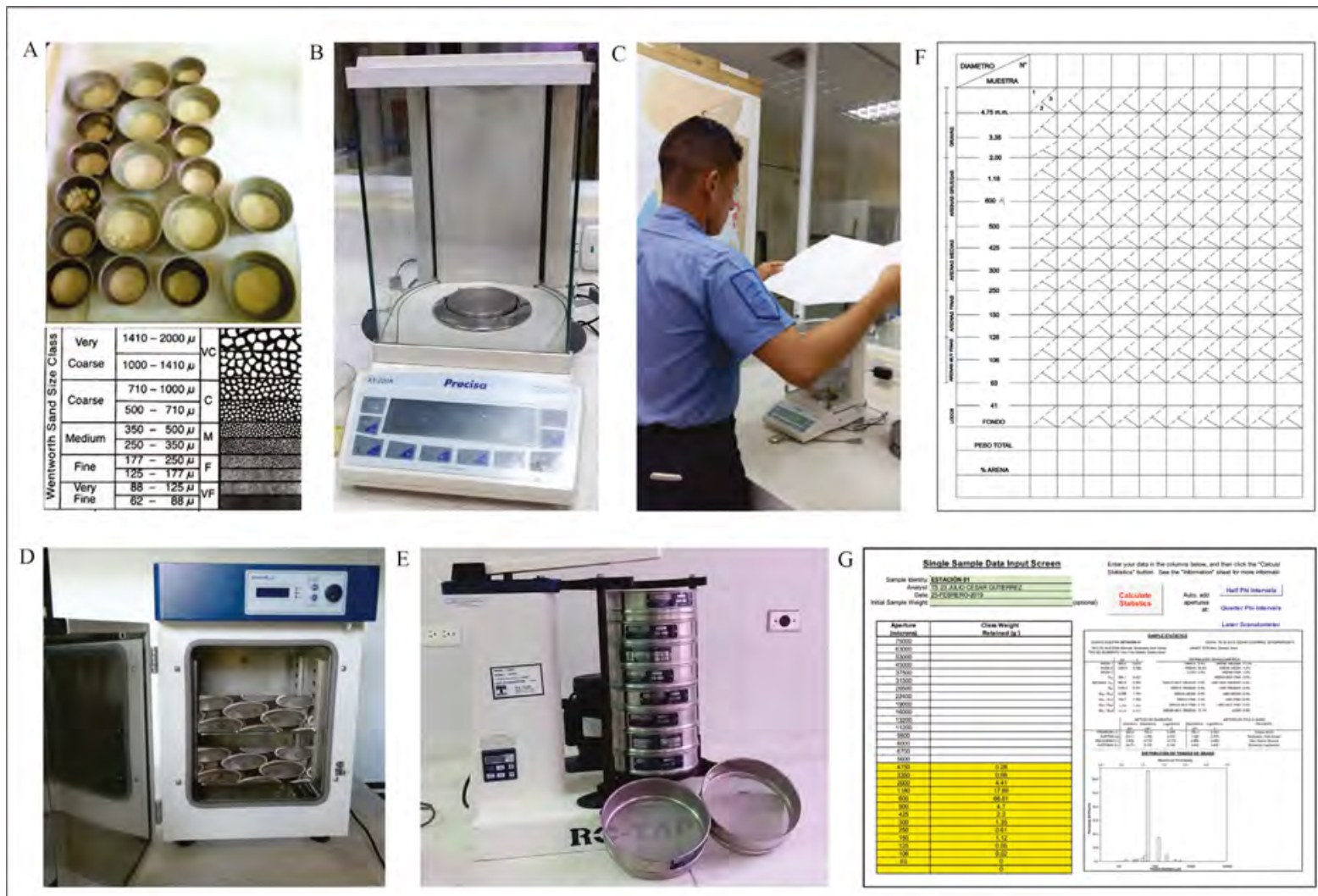

Figura 3. Equipos empleados para la realización de la granulometría. A. Muestras dispuestas para los análisis. B. y C. Equipo digital para pesar los sedimentos. D. Secado de las muestras. E. Columna de tamices y agitador. F. Formato donde se anotan los datos en el tamizado. G. Vista del programa GRADISTAT, a la izquierda donde se agregan los pesos de cada tamiz y a la derecha, presentación de resultados.

\section{Edición de imágenes subacuáticas}

De las 19 estaciones seleccionadas, se obtuvieron 12 videos subacuáticos in situ de buena calidad, cada video tuvo una duración de 1 minuto. Se tuvo en cuenta el código, la hora y fecha de toma registrada por la cámara GoPro Hero. A cada imagen subacuática se le asignó la posición (latitud y longitud) correspondiente, de acuerdo con el número de estación. Se descartaron las imágenes con errores de visualización (desenfocadas). Posteriormente, a las imágenes sobrantes se les realizó un aumento del nivel de los colores RGB (Red, Green, Blue), se filtraron los tonos rojos para resaltar las estructuras del fondo (e.g. parches de coral, Gorgonáceos y arena), se optimizó la saturación y luminosidad para obtener una imagen con mejor contraste, utilizando el software GIMP. 
Unidades geomorfológicas y distribución de facies sedimentarias en la Isla Cayos de Alburquerque, Reserva de Biosfera Seaflower, Caribe colombiano

Tabla 2. Clasificación de los tamaños de grano de Wentworth (1922, modificado de Boggs, 2009).

\begin{tabular}{|c|c|c|c|c|c|c|c|}
\hline \multicolumn{3}{|c|}{$\begin{array}{c}\text { Malla de tamiz } \\
\text { estándar de EE. UU. }\end{array}$} & \multicolumn{2}{|c|}{ Milímetros (mm) } & \multirow{2}{*}{$\begin{array}{c}\text { Unidades de Phi (Ф) } \\
-12\end{array}$} & \multirow[t]{2}{*}{$\begin{array}{c}\text { Clase de tamaño } \\
\text { Wentworth }\end{array}$} & \multirow[t]{2}{*}{ Código } \\
\hline \multirow{9}{*}{\multicolumn{2}{|c|}{ 芯 }} & & 4096 & & & & \\
\hline & & & 1024 & & -10 & \multirow[t]{2}{*}{ Roca } & \multirow[t]{2}{*}{$\mathrm{R}$} \\
\hline & & & 256 & 256 & -8 & & \\
\hline & & & 64 & \multirow{2}{*}{64} & -6 & Adoquín & A \\
\hline & & & 16 & & -4 & \multirow{2}{*}{ Guijarro } & \multirow{2}{*}{$\mathrm{Gj}$} \\
\hline & & 5 & 4 & & -2 & & \\
\hline & & 6 & 3,36 & \multirow{3}{*}{4} & $-1,75$ & \multirow{4}{*}{ Gránulo } & \multirow{4}{*}{ Gr } \\
\hline & & 7 & 2,83 & & $-1,5$ & & \\
\hline & & 8 & 2,38 & & $-1,25$ & & \\
\hline \multirow{20}{*}{\multicolumn{2}{|c|}{ 莺 }} & 10 & 2,00 & \multirow{4}{*}{2} & $-1,0$ & & \\
\hline & & 12 & 1,68 & & $-0,75$ & \multirow{4}{*}{ Arena muy gruesa } & \multirow{4}{*}{ Amg } \\
\hline & & 14 & 1,41 & & $-0,5$ & & \\
\hline & & 16 & 1,19 & & $-0,25$ & & \\
\hline & & 18 & 1,00 & & 0,0 & & \\
\hline & & 20 & 0,84 & \multirow{3}{*}{1} & \multirow[t]{3}{*}{0,25} & \multirow{4}{*}{ Arena gruesa } & \multirow{4}{*}{ Ag } \\
\hline & & 25 & 0,71 & & & & \\
\hline & & 30 & 0,59 & & & & \\
\hline & & 35 & 0,50 & & 1,0 & & \\
\hline & & 40 & 0,42 & $1 / 2$ & 1,25 & & \\
\hline & & 45 & 0,35 & $1 / 2$ & 1,5 & Arona media & Am \\
\hline & & 50 & 0,30 & & 1,75 & 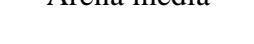 & IIII \\
\hline & & 60 & 0,25 & & 2,0 & & \\
\hline & & 70 & 0,210 & 14 & 2,25 & & \\
\hline & & 80 & 0,177 & $1 / 4$ & 2,5 & Arena fina & Af \\
\hline & & 100 & 0,149 & & 2,75 & 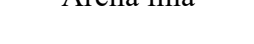 & MII \\
\hline & & 120 & 0,125 & & 3,0 & & \\
\hline & & 140 & 0,105 & $1 / 8$ & 3,25 & & \\
\hline & & 170 & 0,088 & $1 / 0$ & 3,5 & A ron & $\mathrm{mf}$ \\
\hline & & 200 & 0,074 & & 3,75 & 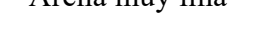 & ก1111 \\
\hline & & 230 & 0,0625 & & 4,0 & & \\
\hline & & 270 & 0,053 & $1 / 16$ & 4,25 & & \\
\hline & & 325 & 0,044 & $1 / 10$ & 4,5 & L imo бruеso & $\mathrm{I} \alpha$ \\
\hline & $\stackrel{\varrho}{\Xi}$ & & 0,037 & & 4,75 & & \\
\hline & 舟 & & 0,031 & $1 / 32$ & 5,0 & & \\
\hline & & & 0,0156 & $1 / 64$ & 6,0 & Limo medio & $\mathrm{Lm}$ \\
\hline 울 & & & 0,0078 & $1 / 128$ & 7,0 & Limo fino & Lf \\
\hline 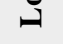 & & & 0,0039 & & 8,0 & Limo muy fino & Lmf \\
\hline & & & 0,0020 & & 9,0 & & \\
\hline & & & 0,00098 & & 10,0 & & \\
\hline & $\stackrel{0}{=}$ & & 0,00049 & $1 / 256$ & 11,0 & A rcilla & Arc \\
\hline & $\frac{5}{4}$ & & 0,00024 & & 12,0 & 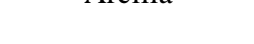 & \\
\hline & & & 0,00012 & & 13,0 & & \\
\hline & & & 0,00006 & & 14,0 & & \\
\hline
\end{tabular}


Tabla 3. Nomenclatura para describir los sedimentos propuesta por Folk (1974, tomado de Franco-Arias et al., 2013).

\begin{tabular}{ccll}
\hline No. & Código textural & \multicolumn{1}{c}{ Clase textural mayor } & \multicolumn{1}{c}{ Clase textural específica } \\
\hline 1 & G & Grava & Grava de guijarros \\
2 & Gs & Grava arenosa & Grava de guijarros arenosa \\
3 & Gsm & Grava arenosa lodosa & Grava de gránulos arenosa lodosa \\
4 & Gm & Grava lodosa & Grava de cantos limosa \\
5 & Sg & Arena gravosa & Arena gruesa guijosa \\
6 & Smg & Arena lodo gravosa & Arena fina limo guijosa \\
7 & Mg & Lodo gravoso & Lodo guijarroso \\
8 & S(g) & Arena ligeramente gravosa & Arena media ligeramente granular \\
9 & Sm(g) & Arena lodosa ligeramente gravosa & Arena media lodosa ligeramente guijosa \\
10 & Ms(g) & Lodo arenoso ligeramente gravoso & Lodo arenoso fino ligeramente granular \\
11 & M(g) & Lodo ligeramente gravoso & Arcilla ligeramente guijosa \\
12 & $\mathrm{~S}$ & Arena (especificar calibrado) & Arena fina bien calibrada \\
13 & $\mathrm{Sm}$ & Arena lodosa & Arena muy fina limosa bien calibrada \\
14 & $\mathrm{Ms}$ & Lodo arenoso & Arcilla arenosa fina \\
15 & $\mathrm{M}$ & Lodo & Limo \\
\hline
\end{tabular}

Tabla 4. Nomenclatura para describir el sedimento, por medio del método logarítmico de Folk y Ward (1957).

\begin{tabular}{|c|c|c|c|c|c|}
\hline \multicolumn{2}{|c|}{ Selección (S) } & \multicolumn{2}{|c|}{ Asimetría (Sk) } & \multicolumn{2}{|c|}{ Angulosidad (K) } \\
\hline Muy bien seleccionado & $<0,35$ & $\begin{array}{l}\text { Asimetría muy } \\
\text { positiva }\end{array}$ & $+1,00 \mathrm{a}+0,30$ & Muy Platicúrtico & $<0,67$ \\
\hline Bien seleccionado & $0,35-0,50$ & Asimetría positiva & $+0,30 \mathrm{a}+0,10$ & Platicúrtico & $0,67-0,90$ \\
\hline $\begin{array}{l}\text { Moderadamente } \\
\text { bien seleccionado }\end{array}$ & $0,51-0,70$ & Simétrica & $+0,10$ a $-0,10$ & Mesocúrtico & $0,90-1,11$ \\
\hline $\begin{array}{l}\text { Moderadamente } \\
\text { seleccionado }\end{array}$ & $0,71-1,00$ & Asimetría negativa & $-0,10$ a $-0,30$ & Leptocúrtico & $1,11-1,50$ \\
\hline $\begin{array}{l}\text { Pobremente } \\
\text { seleccionado }\end{array}$ & $1,00-2,00$ & $\begin{array}{l}\text { Asimetría muy } \\
\text { negativa }\end{array}$ & $-0,30$ a $-1,00$ & Muy Leptocúrtico & $1,50-3,00$ \\
\hline $\begin{array}{l}\text { Muy pobremente } \\
\text { seleccionado }\end{array}$ & $2,00-4,00$ & & & $\begin{array}{l}\text { Extremadamente } \\
\text { Leptocúrtico }\end{array}$ & $>3,00$ \\
\hline $\begin{array}{l}\text { Extremadamente } \\
\text { mal seleccionado }\end{array}$ & $>4,00$ & & & & \\
\hline
\end{tabular}

Tabla 5. Clasificación según el porcentaje de $\mathrm{CaCO}_{3}$ (tomado de Vernette, 1982).

\begin{tabular}{llcc}
\hline Clasificación & \multicolumn{1}{c}{ Descripción } & Código & \%CaCO \\
\hline Litoclástico & Sedimentos terrígenos (origen continental) & $\mathrm{L}$ & $<15$ \\
Litobioclástico & Sedimentos continentales y biológicos con predominio continental & $\mathrm{lb}$ & $15-50$ \\
Biolitoclástico & Sedimentos continentales y biológicos con predominio biológico & bl & $50-85$ \\
Bioclástico & Sedimentos biogénicos & $\mathrm{B}$ & $>85$ \\
\hline
\end{tabular}




\section{Resultados}

\section{Caracterización unidades geomorfológicas}

En el mapa de levantamiento acústico (Figura 4) se observan dos formatos de imagen en vista superficial, el primero en 2D, donde se visualiza dentro de la ICAlb la diferenciación de las unidades geomorfológicas con tonalidades amarillo a anaranjado, generadas por cambios de iluminación. La ICAlb presenta rangos de profundidades que varían entre -0,34 a -164,14 m y un promedio de $-12,80 \mathrm{~m}$. Los valores máximos de profundidad inician desde la periferia del atolón en $-47,224 \mathrm{~m}$. El segundo en 3D, tuvo en cuenta la capa de las profundidades externas a la isla cayos, y se observó un relieve estratificado con profundidades que varían entre $-213,104$ a $-983,12 \mathrm{~m}$.

Dentro del atolón se puede apreciar que en la Cuenca lagunar las profundidades varían entre -0,34 a -47,244 $\mathrm{m}$, con Bajos arrecifales de $-0,34$ a $-6,582 \mathrm{~m}$ (tonalidad amarillo). Alrededor de estos se encuentra la Terraza lagunar que varía entre los -6,582 a -12,716 m (tonalidad amarillo pálido), seguida de una Terraza prearrecifal entre los $-12,678$ a $-26,493 \mathrm{~m}$ (tonalidad anaranjado oscuro) y un Talud rojizo a verde que varía de acuerdo con su profundidad entre los $-26,493$ a $-213,104 \mathrm{~m}$.

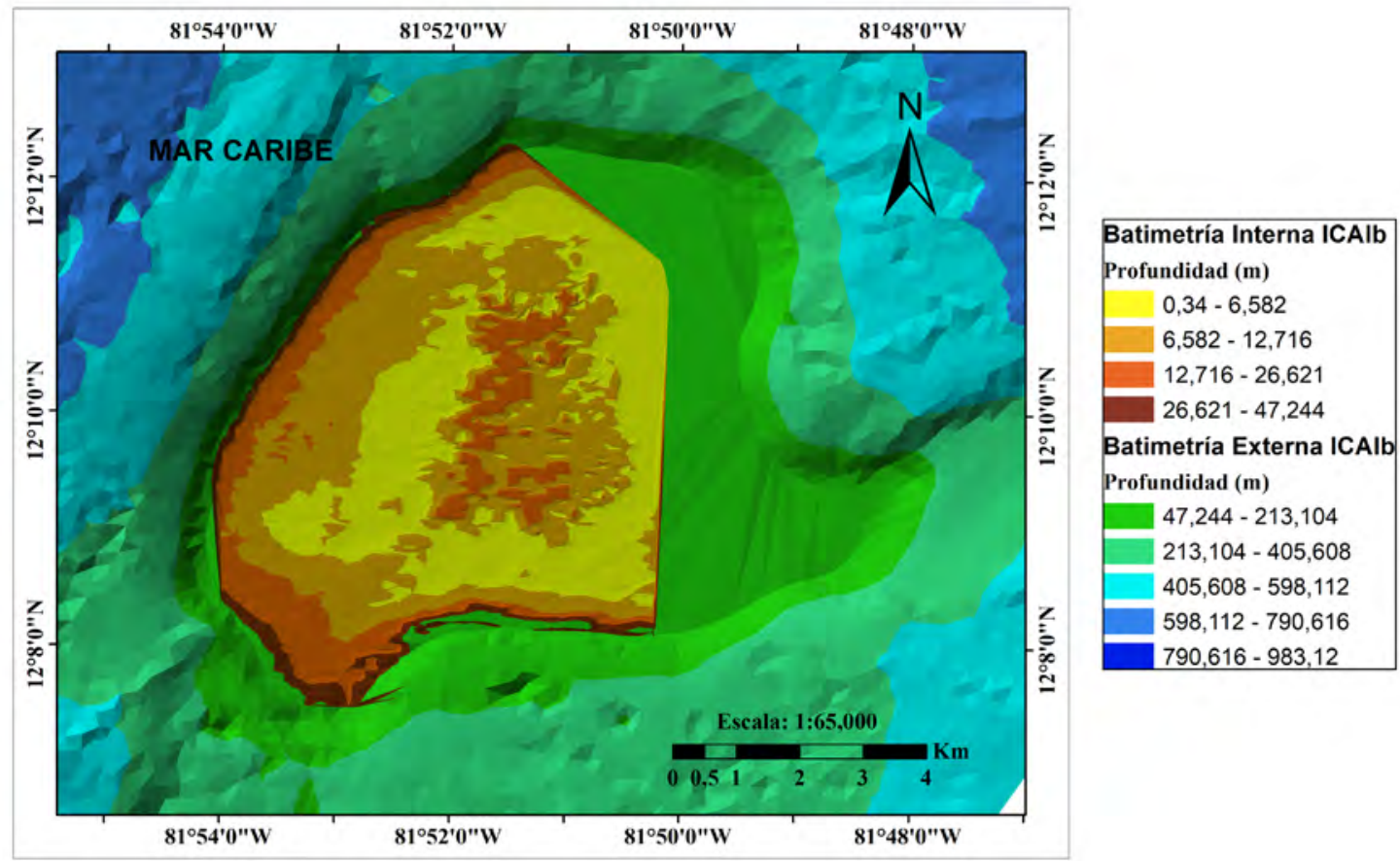

Figura 4. Levantamiento batimétrico en 2D y 3D dentro y fuera de la ICAlb.

El análisis realizado a partir de la generación del MDB, en el uso de las imágenes Worldview-2, y del modelo DOP evidencia que la ICAlb presenta ocho (8) unidades geomorfológicas (Figura 5), caracterizado por un Talud ligeramente inclinado que cambia su ángulo abruptamente dando lugar a un cantil muy pronunciado hacia el margen de sotavento, con un área de $28,5158 \mathrm{~km}^{2}$ y un perímetro de $64,2363 \mathrm{~km}$.

La Terraza prearrecifal de sotavento presenta una profundidad entre 12 a $15 \mathrm{~m}$, comprende un área de $9,8491 \mathrm{~km}^{2}$ y un perímetro de $85,8429 \mathrm{~km}$; presenta arrecifes coralinos mixtos bien consolidados con canales de arena (Tabla 6, E14). El Arrecife periférico de barlovento se extiende en los flancos N, E y SE, tiene un área de 5,8710 $\mathrm{km}^{2} \mathrm{y}$ un perímetro de 64,7784 km; esta área presenta espolones y canales relativamente profundos que se desarrollan más que todo hacía el NE del arrecife a barlovento de la cresta. La Terraza lagunar es relativamente amplia, tiene un área de $17,3091 \mathrm{~km}^{2} \mathrm{y}$ un perímetro de $271,0446 \mathrm{~km}$, casi plana y poco profunda de 1 a $3 \mathrm{~m}$. Muestra una composición de parches de corales blandos (Gorgonáceos) y arenas (Tabla 6, E16, E17 y E20). Las dos islas de arena existentes (tonalidades moradas) presentan un área de $0,0580 \mathrm{~km}^{2}$ y un perímetro de $0,7947 \mathrm{~km}$, y son acumulaciones de sedimentos arrastrados por tormentas sobre la Terraza lagunar. North Cay, la mayor de ellas, sirve actualmente como puesto militar de la Armada de Colombia, y South Cay está separado del anterior por un canal somero de unos $400 \mathrm{~m}$ de ancho y 250 m de largo, y es utilizado por la comunidad pesquera de la isla de San Andrés que viven allí. 
Santiago Martínez-Clavijo; Paula López-Muñoz; Angélica Cabarcas-Mier; Jose Luis Payares-Varela; Julio Gutiérrez; Julián Quintero

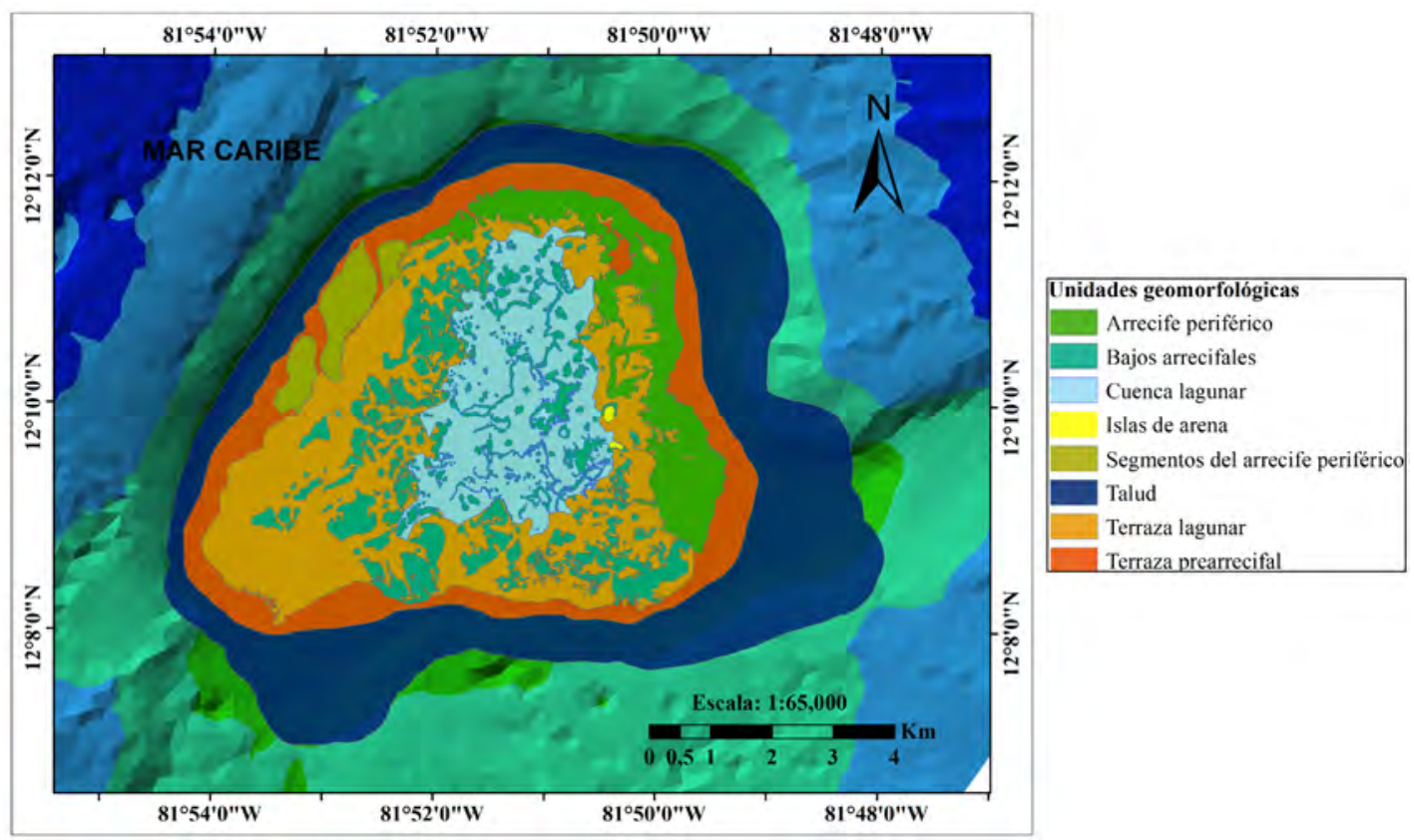

Figura 5. Unidades geomorfológicas de la ICAlb.

Tabla 6. Descripción fotográfica de los fondos marinos en la ICAlb.

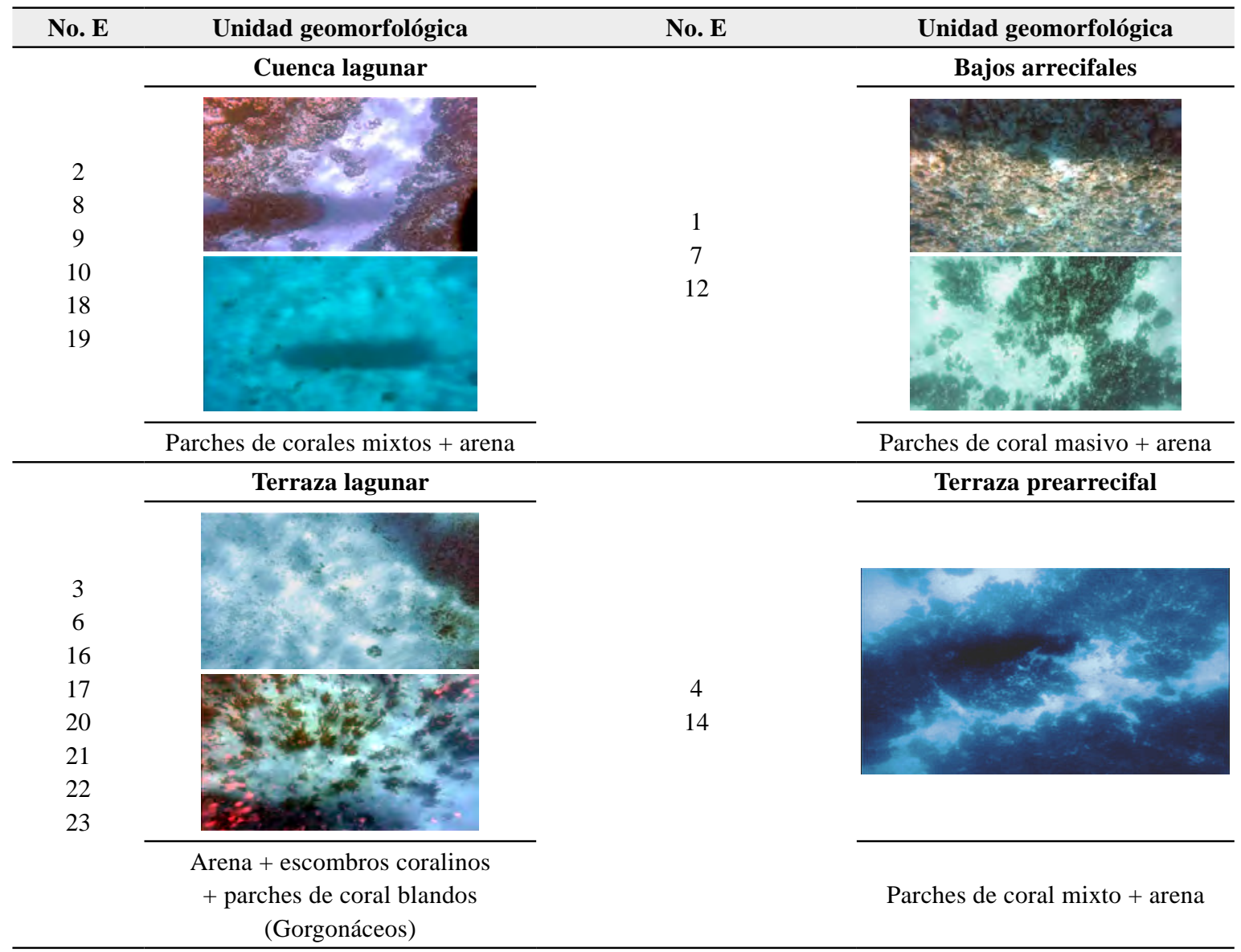


La Cuenca lagunar tiene un área de 8,1862 $\mathrm{km}^{2}$ y 161,5876 km de perímetro; presenta dos niveles batimétricos bien marcados, el primero con $9 \mathrm{~m}$ (localizado hacia la mitad este) y el segundo de $15 \mathrm{~m}$ (en la mitad oeste). Presenta fondos con corales mixtos (masivo, ramificado y esponjas), arrecifes coralinos consolidados y arenas (Tabla 6, E2, E9, E10, E12 y E19). Los contornos de estos dos niveles son fácilmente distinguibles desde el aire por el contraste de dos diferentes tonos de azul (Figura 2). Ambos niveles están separados por Bajos arrecifales, formados por corales masivos (e.g. Orbilla sp., Porites sp.) (Tabla 6, E1, E7, E17) en forma de cinta que recorren, formando meandros, la Cuenca lagunar de norte a sur. Los Bajos arrecifales presentan un área de $8,7820 \mathrm{~km}^{2}$ y un perímetro de 331,5381 km; su ancho no sobrepasa los $30 \mathrm{~m}$ y se elevan hasta los $5 \mathrm{~m}$ por debajo de la superficie del mar.

\section{Distribución del sedimento y facies sedimentarias}

De las 19 estaciones (E) obtenidas, solo dos (2) muestras estaban ubicadas en la Terraza prearrecifal (E4, E14), nueve (9) muestras, en la Terraza lagunar (E3, E6, E7, E16, E17, E20, E21, E22, E23), tres (3) muestras ubicadas en los Bajos arrecifales (E1, E7, E12) y seis (6) en la Cuenca lagunar (E2, E8, E9, E10, E18, E19), como se muestra en la Figura 5.

Se evidencia que la distribución porcentual de los tipos de sedimento es heterogénea; además, se observa que ninguna de las E tuvo sedimentos de tipo R y A. Se obtuvo tipos de sedimento dominantes entre Gj hasta Amf. Sin embargo, la composición de sedimentos de tipo lodo (Lg, Lm, Lf, Lmf y Arc) no fue dominante, así como se muestra en la Tabla 7.

El análisis de clúster arrojó tres grupos y cuatro grupos aislados (Figura 6): el grupo I (G-I) formado por las $\mathrm{E}(1,22,6,7,4,16,12,23,17,20$ y 21$)$; el grupo II (G-II) formado por las E (9 y 14); y el grupo III (G-III) formado por las E (8 y 10). Las E (2, 18, 19 y 3) son grupos aislados con denominación A1, A2, A3 y A4, respectivamente, y no son similares entre sí.

La conformación del G-I se caracterizó por la presencia de Amg, Ag, Am y Af; este grupo estaba ubicado en la Terraza lagunar, Bajos arrecifales y Talud. El G-II se caracterizó por Gr, Amg, Ag, Am, Af, Limos y Arc, ubicados entre Bajos arrecifales y el Talud. En cambio, el G-III y A2, a pesar de carecer de parentesco entre grupos, estuvieron conformados de igual manera por los tipos de sedimentos de Ag, Am, Af, Amf, Limos y Arc, ubicados en los Bajos arrecifales y la Cuenca lagunar. Por su parte, el grupo aislado A1 presentó Am, Af, Limos y Arc, encontrándose en los Bajos arrecifales; el A3 presentó Amf, Limos y Arc, ubicado en la Cuenca lagunar y finalmente el A4, fue el único que presentó mayor porcentualidad de sedimento de Gj (56\%) y en menor proporción de Ag. Este análisis concordó con el diagrama triangular para la clasificación textural según el tamaño de grano definido por Folk (1974) (Figura 7).

Tabla 7. Distribución porcentual de los tipos de sedimento obtenidas en cada estación.

\begin{tabular}{|c|c|c|}
\hline $\begin{array}{c}\begin{array}{c}\text { Siglas de tipo de } \\
\text { sedimento }\end{array} \\
\end{array}$ & $\begin{array}{c}\text { Rango porcentual } \\
(\%) \\
\end{array}$ & Estación \\
\hline Gj & 56 & E3 (A4) \\
\hline $\mathrm{Gr}$ & $>10 \mathrm{a}<20$ & E9 y E14 (G-II) \\
\hline Amg & $>10 \mathrm{a}<30$ & E1, E4, E7 y E22 (G-I); E9 y E14 (G-II) \\
\hline $\mathrm{Ag}$ & $>10$ a $<75$ & $\begin{array}{c}\text { E1, E4, E6, E7, E12, E16, E17, E20, E22 y E23 (G-I); E9 y E14 } \\
\text { (G-II), E8 y E10 (G-III); E3 (A4); E18 (A2) }\end{array}$ \\
\hline Am & $>10$ a $<65$ & $\begin{array}{r}\text { E4, E6, E7, E12, E16, E17, E20, E22 y E23 (G-I); E9 (G-II); E8 y } \\
\text { E10 (G-III); E2 (A1); E18 (A2) }\end{array}$ \\
\hline Af & $>10$ a $<70$ & $\begin{array}{l}\text { E4, E6, E17, E21 (G-I); E9 (G-II); E8 y E10 (G-III); E2 (A1); E18 } \\
\text { (A2) }\end{array}$ \\
\hline Amf & $>10 \mathrm{a}<40$ & E2 (A1); E9 (G-II); E8 y E10 (G-III); E18 (A2); E19 (A3) \\
\hline $\begin{array}{c}\text { Lg } \\
\text { Lm } \\
\text { Lf } \\
\text { Lmf } \\
\text { Arc }\end{array}$ & $\geq 0 \mathrm{a}<5$ & $\begin{array}{l}\text { E4, E12, E16, E21 y E23 (G-I) } \\
\text { E9 (G-II); E8 y E10 (G-III); E2 (A1); E18 (A2), E19 (A3) }\end{array}$ \\
\hline
\end{tabular}




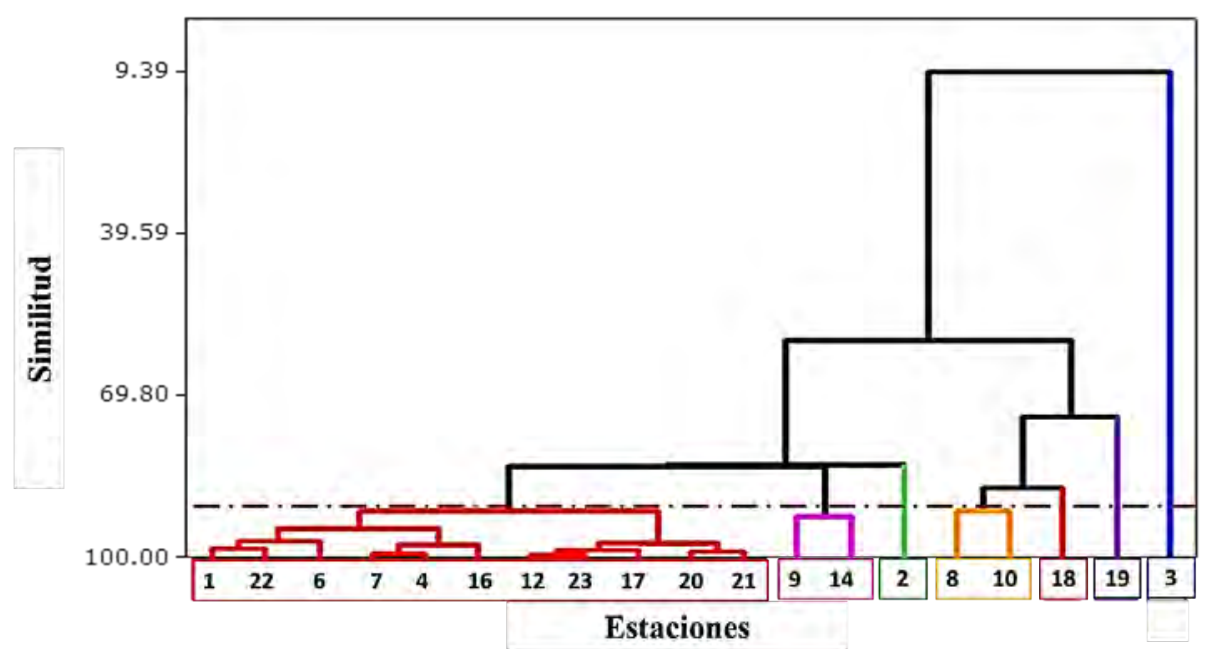

Figura 6. Dendrograma derivado del análisis de clúster a partir de una matriz de similitud a un intervalo de confianza del $90 \%$ (línea punteada).

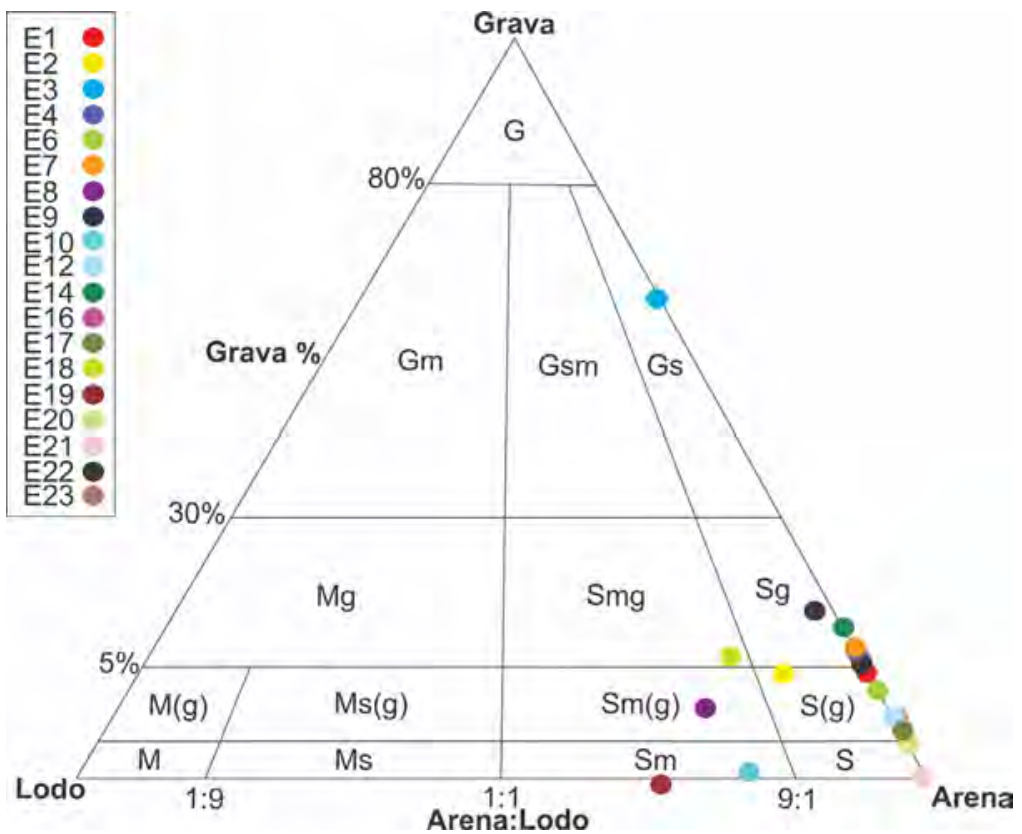

Figura 7. Diagrama triangular para la clasificación textural según el tamaño de grano definido por Folk (1974) de las muestras de sedimento. A la izquierda el listado de las estaciones con su respectivo círculo de ubicación en el triángulo.

Clasificación textural y composicional de las facies sedimentarias

Se han determinado 10 facies sedimentarias (Tabla 8), el Talud presenta una variación en el tamaño de grano de 0,8 a 0,26 $\Phi$ (unidades de phi) con facies que van de SgB a Sgbl de moderada a pobremente seleccionadas y un contenido de $\mathrm{CaCO}_{3}$ entre 50 y $85 \%$ y $>85 \%$. Los tamaños de grano de la Terraza lagunar varían entre -1,34 a 2,31 $\Phi$, de Gs a Ag a Am, con menor proporción Af con facies que varían entre GsB, SgB, Sb, S(g)B, Sgbl, S(g)bl y Sbl de moderada a pobremente seleccionadas, con contenido de $\mathrm{CaCO}_{3}$ entre 50 y $85 \%, y>85 \%$. En cambio, la Cuenca lagunar se caracteriza por presentar una disminución en el tamaño de grano de 2,38 a 4,08 $\Phi$ de Smg a Sm, presentando facies que van de $\mathrm{SmgB}$ a $\mathrm{SmB}$, con un porcentaje de $\mathrm{CaCO}_{3}>85 \%$. Sin embargo, los Bajos arrecifales presentan variaciones en los tamaños de grano de 0,32 a 2,79 $\Phi$, determinadas por $\mathrm{Ag}$ a Af de 
moderada a pobremente seleccionadas, de facies SgB, $\mathrm{S}(\mathrm{g}) \mathrm{bl} \mathrm{y} \mathrm{Sm}(\mathrm{g}) \mathrm{bl}$ con un contenido de $\mathrm{CaCO}_{3}$ entre 50 y $85 \%$, en menor proporción mayores a $85 \%$. En la Figura 9 se presenta el diagrama triangular con los puntos de cada muestra indicando la clasificación textural según el tamaño de grano.

Tabla 8. Resumen de las facies sedimentarias, área, perímetro, contenido de porcentaje $\mathrm{CaCO}_{3}$ y la ubicación en las unidades geomorfológicas.

\begin{tabular}{|c|c|c|c|c|}
\hline Facies & Área $\left(\mathbf{k m}^{2}\right)$ & $\begin{array}{c}\text { Perímetro } \\
(\mathbf{k m})\end{array}$ & $\begin{array}{c}\text { Contenido } \\
\% \mathrm{CaCO}_{3} \\
\end{array}$ & $\begin{array}{c}\text { Ubicación } \\
\text { geomorfológica }\end{array}$ \\
\hline S(g)bl & 4,5532 & 18,1611 & $50-85$ & $\begin{array}{c}\text { Bajos arrecifales } \\
\text { Terraza lagunar }\end{array}$ \\
\hline GsB & 0,116 & 1,5729 & $>85$ & Terraza lagunar \\
\hline SgB & 3,5434 & 27,3722 & $>85$ & $\begin{array}{c}\text { Talud } \\
\text { Terraza lagunar } \\
\text { Bajos arrecifales }\end{array}$ \\
\hline $\mathrm{S}(\mathrm{g}) \mathrm{B}$ & 0,9424 & 7,9013 & $>85$ & Terraza lagunar \\
\hline $\begin{array}{c}\mathrm{Sm}(\mathrm{g}) \\
\mathrm{bl}\end{array}$ & 2,2103 & 12,8973 & $50-85$ & Bajos arrecifales \\
\hline $\mathrm{SmB}$ & 0,9857 & 3,8015 & $>85$ & Cuenca lagunar \\
\hline Sgbl & 2,5473 & 21,227 & $50-85$ & $\begin{array}{c}\text { Talud } \\
\text { Terraza lagunar }\end{array}$ \\
\hline SmgB & 3,0649 & 6,4138 & $>85$ & Cuenca lagunar \\
\hline Sbl & 4,3714 & 30,6509 & $50-85$ & \multirow{2}{*}{ Terraza lagunar } \\
\hline SB & 3,7415 & 31,6233 & $>85$ & \\
\hline
\end{tabular}

\section{Distribución espacial de las facies sedimentarias}

Para la construcción del mapa de distribución de las facies sedimentarias en la ICAlb, se tuvo en cuenta la distribución del contenido de $\mathrm{CaCO}_{3}$ y la granulometría. La metodología utilizada en la elaboración del mapa se basó en la interpolación del método del vecino natural Sibson (1981); se lograron identificar 10 facies sedimentarias distribuidas a lo largo de las unidades geomorfológicas (Figura 8).

Las facies SgB representan el 21\% de las muestras, las cuales están distribuidas en el Talud a una profundidad aproximada de -33 a $-40 \mathrm{~m}$, en la Terraza lagunar y en la barrera arrecifal ubicadas a profundidades menores entre -20 hasta $-27 \mathrm{~m}$ aproximadamente, según la batimetría levantada. Las facies S(g)bl están distribuidas en la Terraza lagunar a profundidades entre $-0,34$ hasta $-20 \mathrm{~m}$ y en la barrera arrecifal entre -13 hasta $-27 \mathrm{~m}$, estas facies representan igualmente $21 \%$ de las muestras adquiridas.
Las facies S(g)B, SmB y Sgbl representan el 31,5\% cada una e indican la misma proporción de 10,5\% de las muestras. La distribución de estas sugiere profundidades de $-0,34$ a $-13 \mathrm{~m}$ para las facies $\mathrm{S}(\mathrm{g}) \mathrm{B}$ en la Terraza lagunar, las facies SmB están ubicadas en la Cuenca lagunar a profundidades mayores entre -13 hasta $-20 \mathrm{~m}$; y con profundidades que van de -13 a $-27 \mathrm{~m}$ se encontraron las facies Sgbl ubicadas en la Terraza lagunar y en el Talud respectivamente. Las facies GsB, SmgB, SB, Sm(g)bl y Sbl representan el $26,31 \%$ de las muestras con la misma proporción de 5,26\% cada una. Las facies GsB están dispuestas en la Cuenca lagunar a profundidades que van de $-0,34$ a $-7 \mathrm{~m}$; las SB, en la Terraza lagunar entre -27 a $-33 \mathrm{~m}$ de profundidad aproximadamente; las facies $\mathrm{Sm}(\mathrm{g}) \mathrm{bl}$, ubicadas en la barrera arrecifal a una profundidad de -13 a -20 m y por último las facies Sbl expuestas en la Terraza lagunar desde -27 hasta $-33 \mathrm{~m}$ de profundidad aproximadamente. 

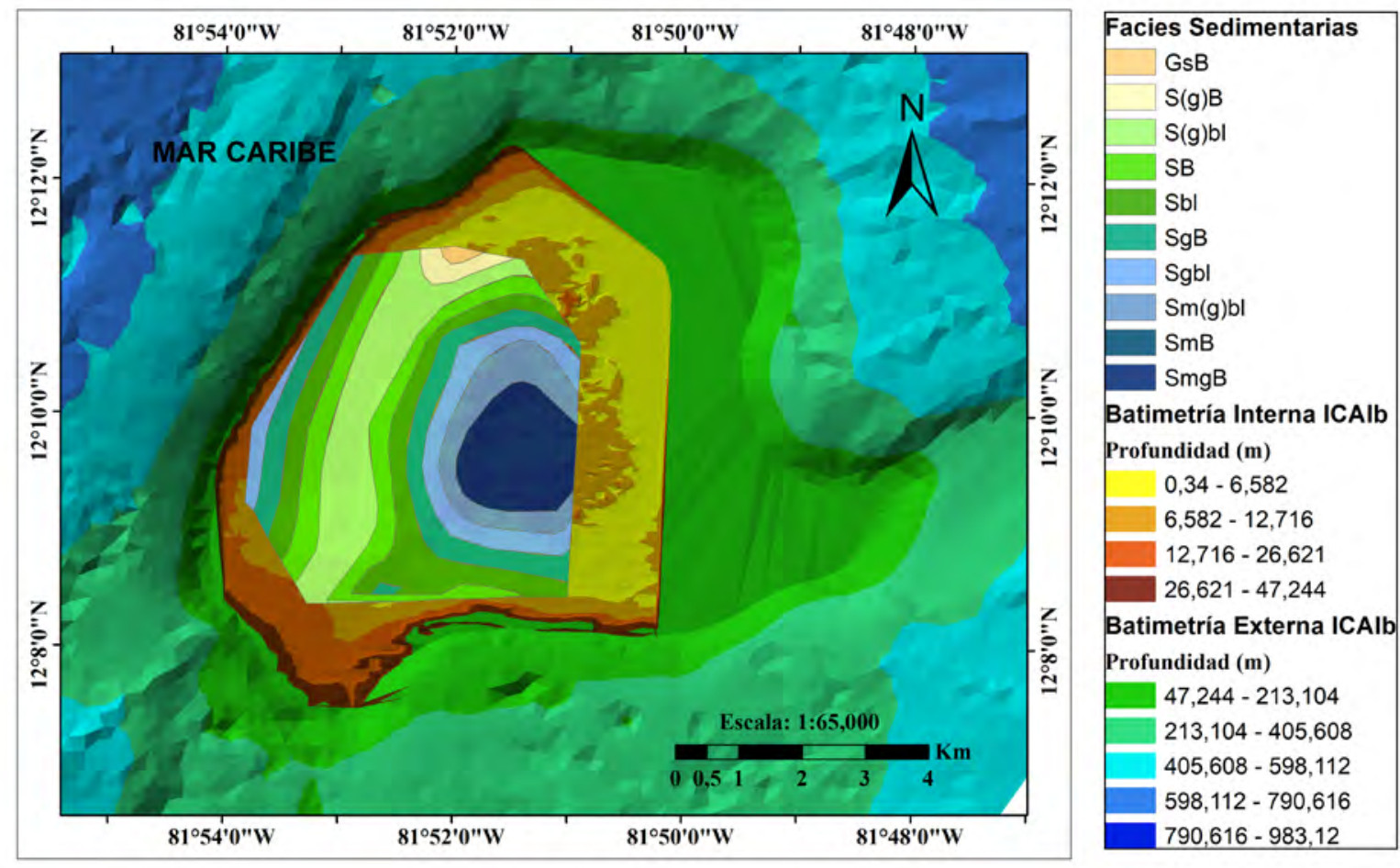

Figura 8. Mapa de Facies sedimentarias de la ICAlb.

\section{Discusión de resultados}

A partir de las técnicas remotas utilizadas en este estudio, se obtuvo la validación y actualización de las unidades geomorfológicas y de la distribución del sedimento en la ICAlb.

El uso de una ecosonda monohaz dentro del atolón permitió obtener cantidad de datos, al cubrir una mayor extensión en las diferentes profundidades que presenta la ICAlb. Se encontró que al vincular esta técnica hidroacústica con las imágenes satelitales, los valores de profundidades generaron una mayor precisión de cada unidad geomorfológica; así mismo, se obtuvieron datos más exactos de las áreas y perímetros de cada una de ellas, con respecto a lo encontrado por Díaz et al. (2000), quienes mostraron que la geomorfología de la ICAlb presenta: Bajos arrecifales con detritos y arenas calcáreos entre 0 a $-3 \mathrm{~m}$; una Cuenca lagunar, con arenas y material detrítico calcáreo, y parches de coral con una profundidad de $-10 \mathrm{~m}$; una Terraza lagunar con arenas de composición calcáreas en -20 m de profundidad; Terraza prearrecifal con arenas calcáreas, costras de algas coralináceas y parches de coral a $30 \mathrm{~m}$ de profundidad y un Talud que se encuentra a $50 \mathrm{~m}$ de profundidad; el Arrecife periférico tiene su formación hacia barlovento y a su vez donde hace incidencia el oleaje es prácticamente continuo y alcanza una longitud de casi $6 \mathrm{~km}$. Por su forma, se considera un sistema de ranura y espolón (Díaz et al., 1996), el cual está bien desarrollado en el sector NE de la isla cayos. Su Terraza prearrecifal se caracteriza por ser muy inclinada que cambia su ángulo abruptamente dando lugar a un cantil muy pronunciado de aproximadamente -20 a 24 m de profundidad; un escalón de -8 a -35 m de ancho, cubierto principalmente por sedimentos calcáreos (Díaz et al., 1996).

El complejo arrecifal de ICAlb, al igual que todos los arrecifes del Archipiélago de San Andrés, Providencia y Santa Catalina, recibe casi permanentemente el impacto del fuerte oleaje generado por los vientos alisios a lo largo de un fetch de casi $2000 \mathrm{~km}$ con velocidades entre 0,5 a $1 \mathrm{~m} / \mathrm{s}$; esta energía considerable es un factor importante que controla en buena parte las características sedimentológicas, el régimen sedimentario y la estructura de la comunidad biológica (Díaz et al., 1996).

En cuanto a las facies sedimentarias, se determinó un alto porcentaje de facies gruesas cercanas al Talud y Bajos arrecifales, presentando una variación composicional de biolitoclásticos a bioclásticos en concordancia con lo determinado por Díaz et al. 
(2000), con un aporte lítico del basamento volcánico y un aporte biogénico de la barrera coralina, además de conchas y fragmentos de material esquelético orgánico (e.g. conchas de bivalvos y/o moluscos), con predominio del aporte de origen biogénico; en la parte central de los Bajos arrecifales hay una disminución del tamaño de grano. Estos sedimentos gruesos están de pobremente a moderadamente seleccionados, indicando un ambiente sedimentario de valores altos de energía cinética en el momento de la depositación. Las facies finas en un bajo porcentaje de distribución se presentan hacia la Cuenca lagunar con un aporte totalmente biogénico mayor al $85 \%$ de $\mathrm{CaCO}_{3}$, presentan una pobre selección y una asimetría positiva que indica valores bajos de energía cinética en el instante de la depositación.

De acuerdo con Díaz et al. (2000), quienes reportan para esta unidad facies gruesas con material detrítico, se establece una diferencia con lo presentado en este estudio, debido tal vez a la interpretación del tamaño de grano, textural y composicional. Las facies en la Terraza lagunar indican un aporte de tamaño de grano fino a grueso (arenas finas a gruesas), pobre a moderadamente seleccionados de origen bioclástico predominantemente como consecuencia de la erosión y la meteorización (Posada et al., 2011; Rangel-Buitrago et al., 2015) que sufren las formaciones arrecifales, producto de las condiciones oceanográficas, tales como las corrientes superficiales en el Caribe suroccidental (Andrade, 2001; Andrade y Desmond, 2013) y el comportamiento del oleaje generado por actividades ciclónicas (Plazas-Moreno et al., 2011), que ocasiona depósitos que incluyen restos de conchas, de corales y de material detrítico, además de presentar un aporte lítico (biolitoclástos) del basamento volcánico en menor proporción. Díaz et al. (2000) proponen para esta unidad geomorfológica gravas y arenas gruesas de composición calcáreas, lo cual coincide con lo planteado por esta investigación en cuanto al tamaño de grano y la composición.

Por otro lado, Triffleman et al. (1992) realizaron el estudio de los sedimentos y los ambientes depositacionales para Isla Cayo Serranilla ubicado al norte de RBS, donde exponen un ambiente de márgenes abiertos hacia el sotavento y una carencia de arrecife de coral a los bordes. Los autores sugieren que, debido a estas condiciones, los sedimentos activos $(80 \%)$ se dirigen hacia el norte, influenciados por fuertes corrientes, y son depositados a las afueras de los bancos y no en las inmediaciones de la Isla Cayo Serranilla. En la ICAlb ocurre todo lo contrario, pues obedece a un sistema semicerrado influenciado por depositaciones de sedimentos biogénicos, los cuales están determinados por los aportes de la barrera coralina y por un aporte terrígeno en menor proporción influenciados por la contribución del basamento volcánico; dichos aportes se encuentran ausentes en la Isla Cayo Serranilla debido a su morfología.

\section{Conclusiones}

A partir de la utilización de las imágenes suministradas por el sensor remoto Worldview-2, los modelos utilizados DOP y MDB, y los criterios seleccionados de Geister y Díaz (2007), se logró generar una cartografía de alta resolución y detalle para la ICAlb; el uso de las diferentes longitudes de onda de luz que penetran en la columna de agua permitió obtener la identificación de las diferentes unidades geomorfológicas.

Las facies sedimentarias en la ICAlb han presentado durante los últimos 20 años un aumento en el tamaño de grano distribuidos hacia el Talud y los Bajos arrecifales, indicando una baja selección de los sedimentos y poco transporte. Esto revela un aporte biolitoclástico con líticos provenientes del basamento volcánico y en mayor proporción, un aporte de material biogénico, debido a la alta tasa de erosión de las formaciones arrecifales y la fragmentación de las conchas de bivalvos y/o moluscos. El tamaño del grano disminuyó hacia la Cuenca lagunar, donde se deduce un ambiente tranquilo de depositación, con un aporte de material en su totalidad biogénico, cuya fuente son los arrecifes coralinos que la rodean. La Terraza lagunar supone un aumento en el tamaño de grano de arena fina a gruesa de composición calcárea, como producto del deterioro de la barrera arrecifal.

Cabe resaltar que la información obtenida en la clasificación geomorfológica y en la distribución de las facies sedimentarias de la ICAlb resultan ser un producto nuevo que aporta al conocimiento encontrado en los fondos marinos presentes en la RBS; esto permite producir planes y protocolos de mejoramiento para la protección, conservación y preservación de esta área marina protegida. A su vez, beneficia al país para sustentar ante la Corte Internacional de Justicia su reclamación en relación con el mar territorial que se encuentra en litigio con Nicaragua.

Se recomienda generar una comprobación in situ de los componentes geológicos y biológicos submarinos, con el fin de identificar cambios que pudieran afectar 
en la geomorfología o en la biodiversidad marina, así como validar a través del tiempo los mapas temáticos generados, y los que se generen de aquí en adelante, para mantener actualizada la base de datos de estos.

\section{Agradecimientos}

Esta investigación se realizó gracias a los aportes de la Armada de Colombia, a través del proyecto 65030 - "Caracterización de la morfología de los fondos marinos y su relación con procesos físicos del océano", el cual forma parte del Portafolio de Fortalecimiento I+D+i de ARC-2018 y al Fondo Francisco José de Caldas - MINCIENCIAS, el cual fue ejecutado por la Facultad de Oceanografía Física de la Escuela Naval de Cadetes 'Almirante Padilla'. A la Comisión Colombiana del Océano, por su compromiso en generar expediciones científicas para actualizar la información de la biodiversidad y de los fondos marinos presentes en la Reserva de Biosfera Seaflower; a la Dirección General Marítima (DIMAR), por proporcionar el apoyo con las plataformas para la investigación científica marina. A la Corporación de Ciencia y Tecnología para el Desarrollo de la Industria Naval Marítima y Fluvial (COTECMAR), por la logística administrada al proyecto. A la Dirección de Ciencia y Tecnología de la Armada de Colombia, por la interlocución entre todos los entes del proyecto, y al Instituto Geológico Agustín Codazzi, por el envío de la imagen satelital de la Isla Cayos de Alburquerque.

\section{Referencias}

Abdulkarim, R.; Akkinigbagbe, A.; Imo, D.; Imhansoloeva, M.; Aniebone, V.; Ibitola, M.; Faleye, B.; Shonde, O.; Appia Y. (2014). Grain size analysis of beach sediment along the barrier bar lagoon coastal system, Lagos, Nigeria; its implication on coastal erosion. Global Journal of Geological Sciences, 12(1), 31-37. https://doi. org/10.4314/gjgs.v12i1.4

Abril-Howard, A.; Bolaños, N.; Machacón, I.; Lasso, J.; Gómez, D.I. (2012). Actualización del conocimiento de los ecosistemas marinos en la Reserva de Biosfera Seaflower, con énfasis en las islas de San Andres y Providencia. En: D.I. GómezLópez, C. Segura-Quintero, P.C. Sierra-Correa, J. Garay-Tinoco, E. Taylor-Jay, O. Bent-Zapata (eds). Atlas de la Reserva de Biósfera Seaflower.
Archipiélago de San Andrés, Providencia y Santa Catalina (pp. 35-60). CORALINA- INVEMAR.

Afanador-Franco, F.; Carvajal-Díaz, A.F.; FrancoArias, D.A.; Orozco-Quintero, F.J.; PachecoGómez, J.D.; Santos-Barrera, Y. (2013). Atlas geomorfológico del litoral Caribe colombiano. DIMAR-CIOH. https://doi.org/10.26640/978958 5772373.2013

Alvarado-Bedoya, O.A. (2014). El conflicto fronterizo entre Colombia y Nicaragua: Recuento histórico de una lucha por el territorio. Historia Caribe, 9(25), 241-271.

Anderson, J.T.; Van Holliday, D.; Kloser, R.; Reid, D.G.; Simard, Y. (2008). Acoustic seabed classification: current practice and future directions. ICES Journal of Marine Science, 65(6), 1004-1011. https://doi.org/10.1093/icesjms/fsn061

Andrade, C.A. (2001). Las corrientes superficiales en la Cuenca de Colombia observadas con boyas de deriva. Revista de la Academia Colombiana de Ciencias Exactas, Físicas y Naturales, 25(96), 321-335.

Andrade, C.A.; Desmond, E. (2013). Sobre la existencia de una celda de circulación atmosférica sobre el Caribe y su efecto en las corrientes de Ekman del Caribe suroccidental. Boletín Cientifico CIOH, 31, 73-94. https://doi. org/10.26640/01200542.31.73_94

Aubouin, J.J.; Azema, J.C.; Carfantan, A.; Demant, C.; Rangin, M.; Tournon, T. (1982a). The Middle America Trench in the geological framework of Central America. Initial Reports of the Deep Sea Drilling Project, 67, 747-755. https://doi. org/10.2973/dsdp.proc.67.141.1982

Aubouin, J.J.; Stephan, J.F.; Roump, J.; Renard, V. (1982b). The Middle America Trench as an example of a subduction zone. Tectonophysics, 86(1-3), 113-132. https://doi.org/10.1016/00401951(82)90063-4

Ball, M.M.; Harrison, C.G.A.; Supko, P.R. (1969). Atlantic opening and the origin of the Caribbean. Nature, 223(5202), 167-168. https://doi. org/10.1038/223167a0 
Blott, S.J.; Pye, K. (2001). GRADISTAT: a grain size distribution and statistics package for the analysis of unconsolidated sediments. Earth Surface Processes and Landforms, 26(11), 1237-1248. https://doi.org/10.1002/esp.261

Boggs, S.Jr. (2009). Petrology of sedimentary rocks. 2nd Edition. Cambridge University Press. https:// doi.org/10.1017/CBO9780511626487

Boschman, L.M.; van Hinsbergen, D.J.J.; Torsvik, T.H.; Spakman, W.; Pindell, J.L. (2014). Kinematic reconstruction of the Caribbean region since the Early Jurassic. Earth-Science Reviews, 138, 102-136. https://doi.org/10.1016/j. earscirev.2014.08.007

Brown, C.J.; Collier, J.S. (2008). Mapping benthic habitat in regions of gradational substrata: An automated approach utilizing geophysical, geological, and biological relationships. Estuarine, Coastal and Shelf Science, 78(1), 203214. https://doi.org/10.1016/j.ecss.2007.11.026

Brown, C.J.; Blondel, P. (2009). Developments in the application of multibeam sonar backscatter for seafloor habitat mapping. Applied Acoustics, 70(10), 1242-1247. https://doi.org/10.1016/j. apacoust.2008.08.004

Calvert, J.; Strong, J.A.; Service, M.; McGonigle, C.; Quinn, R. (2015). An evaluation of supervised and unsupervised classification techniques for marine benthic habitat mapping using multibeam echosounder data. ICES Journal of Marine Science, 72(5), 1498-1513. https://doi. org/10.1093/icesjms/fsu223

Carreño, F.; López, I.; Payán, J.; Arranz, C.; Castellanos, E. (2011). Aplicación del análisis textural a datos de retrodispersión de sonda multihaz para la clasificación de fondos marinos. Revista de Teledetección, 36, 5-19.

Carvajal, A. (2009). Caracterización físico-biótica del litoral del departamento Archipiélago de San Andrés, Providencia y Santa Catalina. En: DIMAR-CIOH. (Ed.). Caracterización físicobiótica del litoral Caribe colombiano (pp. 111138). Capítulo 6, Tomo I. DIMAR.
CCO. (2015). Aportes al Conocimiento de la Reserva de la Biosfera Seaflower. Comisión Colombiana del Océano.

Codazzi, I.G. (2015). Procesamiento digital de imágenes aplicado a manejo de zonas costeras e insulares "Levantamiento cartográfico en zonas insulares mediante imágenes de sensores remotos”. Ministerio de Defensa, Bogotá.

Contreras-Silva, A.I.; López-Caloca, A.A.; TapiaSilva, F.O.; Cerdeira-Estrada, S. (2012). Satellite remote sensing of coral reef habitat mapping in shallow waters at banco Chinchorro reefs, Mexico: a classification Approach. In: B. Escalante (ed.) Remote Sending - Applications (pp. 331-354). InTech. https://doi.org/10.5772/36210

CORALINA. (2004). Agenda ambiental de San Andrés Isla 2004-2020. Sistema de Gestión Ambiental Municipal - SIGAM. Ministerio de Ambiente, Vivienda y Desarrollo Territorial - MAVDT.

Díaz, J.M.; Sánchez, J.A.; Zea, S.; Garzón-Ferreira, J. (1996). Morphology and marine habitats of two southwestern Caribbean atolls: Albuquerque and Courtown. Atoll Research Bulletin, 435, 1-33.

Díaz, J.M.; Barrios, L.M.; Cendales, M.H.; GarzónFerreira, J.; Geister, J.; López-Victoria, M.; Ospina, G.H.; Parra-Velandia, F.; Pinzón, J.; Vargas-Angel, B.; Zapata, F.A.; Zea, S. (2000). Áreas coralinas de Colombia. INVEMAR.

Díaz, J.M. (2005). Esquemas espaciales de zonación ecológica y morfológica de las lagunas de los atolones y complejos arrecifales de un archipiélago oceánico del Caribe: San Andrés y Providencia (Colombia). Revista Académica Colombiana de Ciencias Exactas, Físicas y Naturales, 29(112), 357-369.

Donnelly, T.W. (1989). Geologic history of the Caribbean and Central America. In: A.W. Bally, A.R. Palmar (eds.). The Geology of North America - An overview (pp. 299-323). Geological Society of America. https://doi.org/10.1130/ DNAG-GNA-A.299 
Folk, R.L. (1954). The Distinction between Grain Size and Mineral Composition in Sedimentary-Rock Nomenclature. The Journal of Geology, 62(4), 344-359.

Folk, R.L.; Ward, W.C. (1957). Brazos river bar. A study in the significance of Grain Size Parameters. Journal of Sedimentary Petrology, 27(1), 3-26. https://doi.org/10.1306/74D70646-2B21-11D78648000102C1865D

Folk, R.L. (1974). Petrology of sedimentary rocks. Hemphill Publishing Company Austin.

Franco-Arias, D.A.; Restrepo-López, J.C.; SanabriaRuiz, N.Y; Gutiérrez, J.C. (2013). Caracterización y distribución de facies sedimentarias en la Bahía de Cartagena, Colombia. Boletín de Geología, 35(1), 43-53.

Freitas, R.; Sampaio, L.; Rodriguez, A.M.; Quintino, V. (2005). Sea-bottom classification across a shallow-water bar cannel and near-shore shelf, using single beam acoustics. Estuarine, Coastal and Shelf Science, 65(4), 625-632. https://doi. org/10.1016/j.ecss.2005.07.011

Frisch, W.; Meschede, M.; Sick, M. (1992). Origin of the Central American ophiolites: evidence from paleomagnetic results. GSA Bulletin, 104(10), 1301-1314. https://doi.org/10.1130/00167606(1992)104<1301:OOTCAO >2.3.CO;2

Gamboa, L.; Posada, B.O.; González, O.C.; Hurtado, G.; Andrade-Amaya, C.A. (2012). Geología del Archipiélago de San Andrés, Providencia y Santa Catalina. En: D.I. Gómez-López, C. SeguraQuintero, P.C. Sierra-Correa, J. Garay-Tinoco, E. Taylor-Jay, O. Bent-Zapata (eds). Atlas de la Reserva de Biósfera Seaflower. Archipiélago de San Andrés, Providencia y Santa Catalina (pp. 35-60). CORALINA- INVEMAR.

Garzón-Ferreira, J.; Díaz, J.M. (2003). The Caribbean coral reefs of Colombia. In: J. Cortés (ed.). Latin American Coral Reefs (pp. 275-301). Elsevier Science. https://doi.org/10.1016/B978044451388-5/50013-8

Geister, J. (1975). Reef building and geological evolution of San Andrés Island (western Caribbean Sea, Colombia). Stuttgarter Beiträge zur Naturkunde, Serie B, Geologie und Paläontologie.

Geister, J. (1992). Modern reef development and cenozoic evolution of an oceanic island/reef complex: Isla de Providencia (Western Caribbean Sea, Colombia). Facies, 27(1), 1-69. https://doi. org/10.1007/BF02536804

Geister, J.; Díaz, J.M. (2002). Ambientes arrecifales y geología de un archipiélago oceánico: San Andrés, Providencia y Santa Catalina (mar Caribe, Colombia). Con guía de campo. INGEOMINAS.

Geister, J.; Díaz, J.M. (2007). Reef environments and geology of an oceanic archipielago: San Andrés, Old Providence and Sta. Catalina (Caribbean Sea, Colombia). INGEOMINAS.

González, E. (1987). Oceanografía física descriptiva del archipiélago de San Andrés y Providencia con base en el análisis de 10's cruceros Océano IV a IX. Boletín Cientifico CIOH, 7, 73-100. https:// doi.org/10.26640/01200542.7.73_100

Gutiérrez, S.J.; Bernuil, C. (2004). Manual Sedimentológico. Centro de Investigaciones Oceanográficas e Hidrográficas (CIOH). ENAP. DIMAR. Cartagena. Colombia.

Gutiérrez del Olmo, M.J.; García-Rodríguez, R.; Iglesias-Martínez, L.; De la Vega-Panizo, R.; Rincones-Salinas, M. (2013). Análisis exploratorio de firmas espectrales e índices de vegetación para la monitorización de emisiones de $\mathrm{CO}_{2}$ en un análogo natural. XV Congreso de la Asociación Española de Teledetección INTA, Madrid, España.

Idárraga-García, J.; León, H. (2019). Unraveling the Underwater Morphological Features of Roncador Bank, Archipelago of San Andres, Providencia and Santa Catalina (Colombian Caribbean). Frontiers in Marine Science, 6(77), 1-16. https:// doi.org/10.3389/fmars.2019.00077

Idárraga-García, J.; García-Varón, J.; León, H. (2021). Submarine geomorphology, tectonic features and mass wasting processes in the archipelago of San Andres, Providencia and Santa Catalina (western Caribbean). Marine Geology, 435. https://doi. org/10.1016/j.margeo.2021.106458 
Ierodiaconou, D.; Monk, J.; Rattray, A.; Laurenson, L.; Versace, V.L. (2011). Comparison of automated classification techniques for predicting benthic biological communities using hydroacoustics and video observations. Continental Shelf Research, 31(2), S28-S38. https://doi.org/10.1016/j. Csr.2010.01.012

IGAC (2016-2017). Imagen satelital de la Isla Cayos Alburquerque, Reserva de la Biosfera Seaflower. 1:1. Bogotá D.C., Colombia. Instituto Geográfico Agustín Codazzi.

IGAC. (2007). Fundamentos físicos en teledetección. Instituto Geográfico Agustín Codazzi.

James, K.H. (2006). Arguments for and against the Pacific origin of the Caribbean Plate: discussion, finding for an inter-American origin. Geologica Acta, 4(1-2), 279-302. https://doi. org/10.1344/105.000000370

Kench, P.S.; Brander, R.W. (2006). Wave processes on coral reef flats: implications for reef geomorphology using Australian case studies. Journal of Coastal Research, 221, 209-223. https://doi.org/10.2112/05A-0016.1

Kenny, A.; Cato, I.; Desprez, M.; Fader, G.; Schuttenhelm, R.; Side, J. (2003). An overview of seabed-mapping technologies in the context of marine habitat classification. ICES Journal of Marine Science, 60(2), 411-418. https://doi. org/10.1016/S1054-3139(03)00006-7

Klitgord, K.D.; Schouten, H. (1986). Plate kinematics of the central Atlantic. In: P.R. Vogt, B.E. Tucholke (eds.). The Western North Atlantic Region (pp. 351-378). Geological Society of America. https:// doi.org/10.1130/DNAG-GNA-M.351

Krumbein, W.C.; Pettijohn, F.J. (1938). Manual of Sedimentary Petrography. D. Appleton-Century.

Li, Y.; Zou, X.; Ge, C.; Tan, M.; Tang. M.; Liu, X.; Wang, L.; Liu, Y.; Wang, X. (2020). Age and sedimentary characteristics of beach sediments from Yongle Atoll, South China Sea: Implications for sediments supply in a coral reef system. Journal of Asian Earth Sciences, 187. https://doi. org/10.1016/j.jseaes.2019.104083
López-Orrego, G.; De Mello, C.; Marín, Y. (2011). Mapeo del fondo marino del talud continental superior y medio de Uruguay. Conferencia Reunión Regional de Acústica -AUA. 1-9.

Mann, P. (1999). Caribbean sedimentary basins: classification and tectonic setting from jurassic to present. Sedimentary Basins of the World, 4, 3-31. https://doi.org/10.1016/S1874-5997(99)80035-5

Martínez-Clavijo, S. (2013). Diagnóstico actualizado y propuestas de manejo integrado para el Balneario "El Rodadero", Santa Marta, Caribe colombiano. Tesis, Universidad Jorge Tadeo Lozano, Bogotá, Colombia.

Medialdea, T.; Somoza, L.; León, R.; Farrán, M.; Ercilla, G.; Maestro, A.; Casas, D.; Llave, E.; Hernández-Molina, F.J.; Fernández-Puga, M.C.; Alonso, B. (2008). Multibeam backscatter as a tool for sea-floor characterization and identification of oil spills in the Galicia Bank. Marine Geology, 249(1-2), 93-107. https://doi.org/10.1016/j. margeo.2007.09.007

Meschede, M.; Frisch, W. (1998). A plate-tectonic model for the Mesozoic and early Cenozoic history of the Caribbean plate. Tectonophysics, 296(3-4), 269-291. https://doi.org/10.1016/ S0040-1951(98)00157-7

Milliman, J.D. (1969). Four southwestern Caribbean atolls: Courtown Cays, Albuquerque Cays, Roncador Bank and Serrana Bank. Atoll Research Bulletin, 129, 1-26. https://doi.org/10.5479/ si.00775630.129.1

Ostrovsky, I.; Tęgowski, J. (2010). Hydroacoustic analysis of spatial and temporal variability of bottom sediment characteristics in Lake Kinneret in relation to water level fluctuation. Geo-Marine Letters, 30(3-4), 261-269. https://doi.org/10.1007/ s00367-009-0180-4

Pantoja-Benavides, J.F.; Giraldo-Ramos, F.N.; RubioValderrama, Y.S.; Rojas-Lara, V.M. (2010). Segmentación de imágenes utilizando campos aleatorios de Markov. Visión Electrónica, 4(2), 5-16. https://doi.org/10.14483/22484728.432 
Paschke, J.F. (2010). Clasificación de los fondos del Golfo de Urabá empleando métodos acústicos. Tesis, Universidad EAFIT. Escuela de Ciencias Básicas. Medellín, Colombia.

Perry, C.T.; Smithers, S.G.; Roche, R.C.; Wassenburg, J. (2011). Recurrent patterns of coral community and sediment facies development through successive phases of Holocene inner-shelf reef growth and decline. Marine Geology, 289(1-4), 6071. https://doi.org/10.1016/j.margeo.2011.09.012

Pindell, J.L.; Barrett, S.F. (1991). Geologic evolution of the Caribbean region; a plate-tectonic perspective. In: G. Dengo, J.E. Case (Eds.). The Caribbean region (pp. 405-432). The Geological Society of America. https://doi.org/10.1130/ DNAG-GNA-H.405

Pindell, J.L.; Kennan, L.; Maresch, W.V.; Stanek, K.P.; Draper, G.; Higgs, R. (2005). Plate-kinematics and crustal dynamics of circum-Caribbean arccontinent interactions: Tectonic controls on basin development in Proto-Caribbean margins. In: H.G. Avé, V.B. Sisson (eds.). Caribbean-South American plate interactions, Venezuela (pp. 7-52). Geological Society of America. https://doi. org/10.1130/0-8137-2394-9.7

Pindell, J.L.; Kennan, L. (2009). Tectonic evolution of the Gulf of Mexico, Caribbean and northern South America in the mantle reference frame: An update. Geological Society, London, Special Publications, 328, 1-55. https://doi.org/10.1144/ SP328.1

Plazas-Moreno, J.M.; Ortíz-Royero, J.C.; Lizano, O.G. (2011). Evaluación de la actividad ciclónica y el impacto del oleaje en la Isla de San Andrés desde 1851 hasta 2010. Boletín Cientifico $\mathrm{CIOH}$, 29, 8-26. https://doi.org/10.26640/22159045.226

Posada, B.O.; Morales-Giraldo, D.; Henao, P. (2011). Diagnóstico de la erosión costera del territorio insular colombiano. INVEMAR.

Rangel-Buitrago, N.G.; Anfuso, G.; Williams, A.T. (2015). Coastal erosion along the Caribbean coast of Colombia: Magnitudes, causes and management. Ocean \& Coastal Management, $114, \quad 129-144 . \quad$ https://doi.org/10.1016/j. ocecoaman.2015.06.024
Rankey, E.C. (2011). Nature and stability of atoll island shorelines: Gilbert Island chain, Kiribati, equatorial Pacific. Sedimentology, 58(7), 1831-1859. https://doi.org/10.1111/j.13653091.2011.01241.x

Rao, T.R. (2008). Geological evolution of the Caribbean plate: Some critical aspects in the two divergent models. Current Science, 95(6), 736742.

Restrepo, I.C.; Ojeda, G.Y.; Correa, I.D. (2007). Geomorfología de la plataforma somera del departamento de Córdoba, costa Caribe colombiana. Boletín de Ciencias de la Tierra, 20, 39-52.

Rojas, J. (2015). El fallo de La Haya y sus efectos en la Reserva de Biosfera Seaflower. Revista Zero Online. Contraseña.

Ross, M.I.; Scotese, C.R. (1988). A hierarchical tectonic model of the Gulf of Mexico and Caribbean region. Tectonophysics, 155(1-4), 139-168. https://doi.org/10.1016/0040-1951(88)90263-6

Sánchez, J.A.; Pizarro, V.; Acosta de Sánchez, A.; Castillo, P.; Herron, P.; Martínez, J.; Montoya, P.; Orozco C. (2005). Evaluating coral reef benthic communities in remote Caribbean atolls (Quitasueño, Serrana, and Roncador Banks) to recommend marine protected areas for the Seaflower Biosphere Reserve. Atoll Research Bulletin, 531, 1-65. https://doi.org/10.5479/ si.00775630.531.1

Santos-Martínez, A.; Hinojosa, S.; Sierra-Rozo, O. (2009). Proceso y avance hacia la sostenibilidad ambiental: la Reserva de la Biosfera Seaflower, en el Caribe colombiano. Cuadernos del Caribe, 13, 7-23.

Sibson, R. (1981). A Brief Description of Natural Neighbor Interpolation. In: V. Barnett (Ed.) Interpreting Multivariate Data (pp. 21-36). John Wiley \& Sons.

Sykes, L.R.; McCann, W.R.; Kafka, A.L. (1982). Motion of Caribbean Plate during last 7 million years and implications for earlier Cenozoic movements. Journal of Geophysical Research: Solid Earth, 87(B13), 10656-10676. https://doi. org/10.1029/JB087iB13p10656 
Triffleman, N.J.; Hallock, P.; Hine, A.C. (1992). Morphology, sediments, and depositional environments of a small carbonate platform: Serranilla Bank, Nicaraguan Rise, Southwest Caribbean Sea. Journal of Sedimentary Petrology, 62(4), 591-606. https://doi.org/10.1306/ D426796A-2B26-11D7-8648000102C1865D

Venkatramanan, S.; Ramkumar, T.; Anitha-Mary, I. (2011). Grain size statistical parameters of coastal sediments around Tirumalairajanar River Mouth, Tamilnadu, East Coast of India. Journal of Indian Association of Sedimentologists, 30(1), 65-73.

Vernette, G. (1982). Estandarización de los criterios sedimentológicos para la cartografía de la plataforma continental. Boletín Cientifico $\mathrm{CIOH}$, 4, 3-13.

Wentworth, C.K. (1922). A scale of grade and class terms for clastic sediments. The Journal of Geology, 30(5), 377-392.

Woodroffe, C.D. (2008). Reef-island topography and the vulnerability of atolls to sea-level rise. Global and Planetary Change, 62(1-2), 77-96. https:// doi.org/10.1016/j.gloplacha.2007.11.001

Fecha de recibido: 26 de noviembre de 2020 Fecha de aprobado: 28 de julio de 2021 